\title{
FAST REACTOR PHYSICS AND COMPUTATIONAL METHODS
}

\author{
W. S. YANG \\ Purdue University School of Nuclear Engineering \\ West Lafayette, IN 47907, USA \\ *Corresponding author. E-mail : yang494@purdue.edu \\ Invited March 23, 2011 \\ Received November 26, 2011 \\ Accepted for Publication December 12, 2011
}

This paper reviews the fast reactor physics and computational methods. The basic reactor physics specific to fast spectrum reactors are briefly reviewed, focused on fissile material breeding and actinide burning. Design implications and reactivity feedback characteristics are compared between breeder and burner reactors. Some discussions are given to the distinct nuclear characteristics of fast reactors that make the assumptions employed in traditional LWR analysis methods not applicable. Reactor physics analysis codes used for the modeling of fast reactor designs in the U.S. are reviewed. This review covers cross-section generation capabilities, whole-core deterministic (diffusion and transport) and Monte Carlo calculation tools, depletion and fuel cycle analysis codes, perturbation theory codes for reactivity coefficient calculation and cross section sensitivity analysis, and uncertainty analysis codes.

KEYWORDS : Fast Reactor Physics, Reactivity Coefficients, Neutronics Analysis Methods

\section{INTRODUCTION}

Six advanced reactor concepts have been selected for Generation-IV reactors and are being investigated worldwide to meet the challenging goals of effective resource utilization and waste minimization (sustainability), improved safety, enhanced proliferation resistance, and reduced system cost. [1] The six systems are very high temperature reactor (VHTR), sodium-cooled fast reactor (SFR), supercritical water-cooled reactor (SCWR), gascooled fast reactor (GFR), lead-cooled fast reactor (LFR), and molten salt reactor (MSR). Most of the six systems employ a closed fuel cycle to maximize uranium resources and minimize high-level wastes to be sent to a repository. Three of the six are fast reactors (SFR, LFR and GFR), one (SCWR) can be built as a fast reactor, and one (MSR) is described as epithermal. Under the Generation-IV International Forum (GIF) framework, international collaboration on fast reactor designs is proceeding with high priority. [2]

Fast reactors have intrinsic nuclear characteristics that offer greatly more efficient use of uranium resources and the ability to burn actinides which are the long-lived component of high-level nuclear wastes. Combination of the increased fission-to-capture ratio and the increased number of neutrons per fission in fast neutron region yields more excess neutrons from ${ }^{239} \mathrm{Pu}$ fission, which can be captured in ${ }^{238} \mathrm{U}$ to breed more ${ }^{239} \mathrm{Pu}$. While current Generation-III commercial reactors utilize less than one percent of uranium resources, fast reactors can utilize essentially all fissile and fertile isotopes through recycling, except for small losses in processing, resulting in a hundred-fold improvement. Compared to thermal spectrum reactors, fast spectrum reactors are much more efficient in destroying actinides because of higher fission-to-capture reaction ratios. Thus the hazardous transuranics (TRU) elements of used nuclear fuel can be removed from the waste stream and subsequently transmuted to shorterlived fission products in fast reactors while producing about one MW-day (MWD) of energy for every gram. The transmutation of TRU would reduce the long-term environment burden of nuclear energy through significant reduction of released dose and radiotoxicity and efficient utilization of permanent disposal space.

Fast reactors for production of fuel and electricity were conceived by Fermi and his team as early as April 26, 1944. [3] The world's first plutonium-fueled nuclear reactor Clementine was designed and built in 1945-46 and first achieved criticality in late 1946. [4] The Experimental Breeder Reactor I (EBR-I) generated the world's first useful electricity from nuclear power on December 20, 1951 and demonstrated the breeding principle in 1953. The Experimental Breeder Reactor II (EBR-II) was the first power reactor system in the United States power 
demonstration program to operate on a closed fuel cycle utilizing recycled fuel. Between 1964 and 1969, about 35,000 fuel rods were reprocessed using the pyroprocessing based on melt-refining and remotely refabricated in the adjoining fuel cycle facility. [5, 6] During the processing period, the average throughput was about $100 \mathrm{~kg} / \mathrm{month}$. Peak throughput occurred in mid-1967 and was 245 $\mathrm{kg} / \mathrm{month}$. The average turnaround time was about two months from discharge to reload into the reactor. The Phénix reactor also performed the fuel cycle loop several times by reprocessing 25 tons of used fuel at the Marcoule Pilot Plant and the Cogéma plant in La Hague. [7] The EBR-II shutdown heat removal tests conducted in April 1986 also demonstrated inherent passive safety potential of sodium-cooled, metal-fueled, pool-type reactors against double-fault accidents such as unprotected (without scram) loss-of-flow and loss-of-heat sink from full power and flow. [8]

About 20 fast reactors have been operated worldwide, and about 400 reactor-years of operating experience have been accumulated to the end of 2010. [9] The fast reactor was originally conceived to utilize uranium more efficiently and thus extend the world's uranium resources. The conventional fast reactors built so far are generally fast breeder reactors (FBRs), implying a net increase in ${ }^{239} \mathrm{Pu}$ from breeding. These have fertile blankets of depleted uranium $\left({ }^{238} \mathrm{U}\right)$ around the core to maximize ${ }^{239} \mathrm{Pu}$ breeding. However, fast reactor concepts being developed for the Generation IV program will not have separate blankets to enhance proliferation resistance.

During the past 20 years there has been stagnation in the development of commercial fast reactors in the industrialized countries that were involved earlier in intensive development of this area. However, the interest in fast reactors has been renewed along with the nuclear renaissance around the world; in particular due to their ability to fission actinides, including those which may be recovered from thermal reactor used fuel. India is constructing a 500 MWe Prototype Fast Breeder Reactor (PFBR), which is expected to be operating by 2012 . Subsequently four more units of the same size are planned in two sites by 2020 . Initial cores will have mixed oxide fuel but these will be followed by metallic fuelled ones to enable shorter doubling time. China has recently constructed the Chinese Experimental Fast Reactor (CEFR), which achieved the initial criticality on July 21, 2010 and was connected to grid in July 2011 at $40 \%$ of power. In October 2009, China signed an agreement with Russia to start pre-project and design works for a commercial nuclear power plant with two BN-800 reactors, with construction to start in 2013 and commissioning 2018-19. Both China and India envision rapidly growing demand for nuclear and consider fast breeder reactors to be essential part of their future energy mix.

Russia has resumed the construction of BN-800 to be online in 2014 and have plans for follow-on plants. It is also planned to build a multi-purpose research reactor (MBIR) with targeted startup in 2019, and to reconfigure the BN-600 by replacing the fertile blanket around the core with steel reflector assemblies to burn the plutonium from its military stockpiles and to extend its life beyond the 30-year design span. Japan envisions commercial fast reactors by 2050 and plans to construct a demo plant by 2025. Mitsubishi FBR Systems (MFBR) is designated as the responsible entity to build the Japan Standard Fast Reactor (JSFR) concept, with breeding ratio around 1.1. France envisions commercial fast reactors by 2045, and plans a demo plant by 2020. The specification for the Advanced Sodium Technological Reactor for Industrial Demonstration (ASTRID) is to be done by 2012, with final decision on construction to be made in 2017. South Korea is developing a 600 MWe KALIMER design. The U.S. also renewed its interest in fast reactors, but it is standing back from new plants and research is focused on cost reduction and performance improvements, assurance of safety to promote design simplification and licensing, and high system reliability.

In this paper, we review the basic reactor physics specific to fast spectrum reactors and the associated computational methods. Section 2 presents the basic fast reactor physics focused on breeding and actinide burning capabilities, design implications, and reactivity feedbacks. Computational methods and codes specific to fast reactor physics analysis are discussed in Section 3. Section 4 provides some conclusions.

\section{BASIC FAST REACTOR PHYSICS}

\subsection{Breeding Ratio}

As aforementioned, the fast reactor was originally conceived to breed nuclear fuel by converting abundant fertile materials to fissile materials. Breeding of nuclear fuel is achieved by two nuclear conversion processes in which a fissile nucleus is produced by neutron capture in a fertile nucleus. In the two known breeding processes, ${ }^{238} \mathrm{U}$ is converted into ${ }^{239} \mathrm{Pu}$, and ${ }^{232} \mathrm{Th}$ into ${ }^{233} \mathrm{U}$ as shown in the following reaction equations:

$$
\begin{aligned}
& { }^{232} \mathrm{Th}(n, \gamma){ }^{233} \mathrm{Th} \underset{{ }^{-}}{\stackrel{\beta^{-}}{22.2 \mathrm{~m}}}{ }^{233} \mathrm{~Pa} \underset{{ }^{-}}{\stackrel{\beta^{-}}{27.4 \mathrm{~d}}}{ }^{233} \mathrm{U} \\
& { }^{238} \mathrm{U}(n, \gamma){ }^{239} \mathrm{U} \underset{23.5 \mathrm{~m}}{\stackrel{\beta^{-}}{\longrightarrow}}{ }^{239} \mathrm{~Np} \underset{2.35 \mathrm{~d}}{\stackrel{\beta^{-}}{\longrightarrow}}{ }^{239} \mathrm{Pu}
\end{aligned}
$$

Both breeding processes are continued in practical reactor applications by subsequent neutron capture reactions: ${ }^{233} \mathrm{U}(n, \gamma){ }^{234} \mathrm{U},{ }^{234} \mathrm{U}(n, \gamma){ }^{235} \mathrm{U},{ }^{235} \mathrm{U}(n, \gamma){ }^{236} \mathrm{U}$, etc. and ${ }^{239} \mathrm{Pu}(n, \gamma){ }^{240} \mathrm{Pu},{ }^{240} \mathrm{Pu}(n, \gamma){ }^{241} \mathrm{Pu},{ }^{241} \mathrm{Pu}(n, \gamma){ }^{242} \mathrm{Pu}$, etc.

A conversion process is quantitatively described in terms of the conversion ratio $C$, which is defined as the average number of fissile nuclides produced in a reactor per fissile nuclide consumed; when $C>1$, it is called the breeding ratio. The breeding capability of a reactor can 
be estimated using the neutron balance equation:

$$
L+A_{\text {fissile }}+A_{\text {fertile }}+A_{\text {others }}=v F_{\text {fissile }}+v F_{\text {fertile }}
$$

where $L$ is the leakage rate, $A_{x}$ is the absorption rate in material $x$, and $v F_{x}$ is the production rate due to fission of material $x$. By normalizing the balance equation to the neutron absorption in fissile isotopes, we have

$$
\begin{gathered}
\frac{A_{\text {fertile }}}{A_{\text {fissile }}}=\frac{v F_{\text {fissile }}}{A_{\text {fissile }}}-1+\frac{v F_{\text {fertile }}}{A_{\text {fissile }}}-\frac{A_{\text {others }}}{A_{\text {fissile }}}-\frac{L}{A_{\text {fissile }}} \\
C=(\eta-1)+\varepsilon-\left(l_{A}+l_{L}\right)
\end{gathered}
$$

where $\eta$ is the number of neutrons produced by fissions in fissile isotopes, $\varepsilon$ is the number of excess neutrons produced by fissions in fertile isotopes, $l_{A}$ is the number of neutrons absorbed in non-fuel materials, and $l_{L}$ is the number of neutrons lost by leakage. Including the decay loss of fissile isotopes during irradiation (e.g. ${ }^{241} \mathrm{Pu}$ decay to ${ }^{241} \mathrm{Am}$ ), which is independent of neutron balance, Eq. (4) becomes

$$
C=(\eta-1)+\varepsilon-\left(l_{A}+l_{L}+l_{D}\right)
$$

Equation (5) shows that the number of neutrons produced by fissile isotope fission per neutron absorption in fissile isotopes $(\eta)$ plays a central role in determining the conversion or breeding ratio. For breeding, $\eta$ must be substantially greater than 2 since one fission neutron must eventually be absorbed in fuel to keep the chain reaction critical and more than one neutron must be absorbed in fertile material to produce the new fissile isotope. Fig. 1 compares $\eta(E)$ for three fissile isotopes based on the ENDF/B-VII.0 data [10]. It can be seen that $\eta$ of ${ }^{239} \mathrm{Pu}$ is substantially larger than 2 in the energy range above $\sim 100$ $\mathrm{keV}$ and rapidly increases with increasing energy. Therefore,

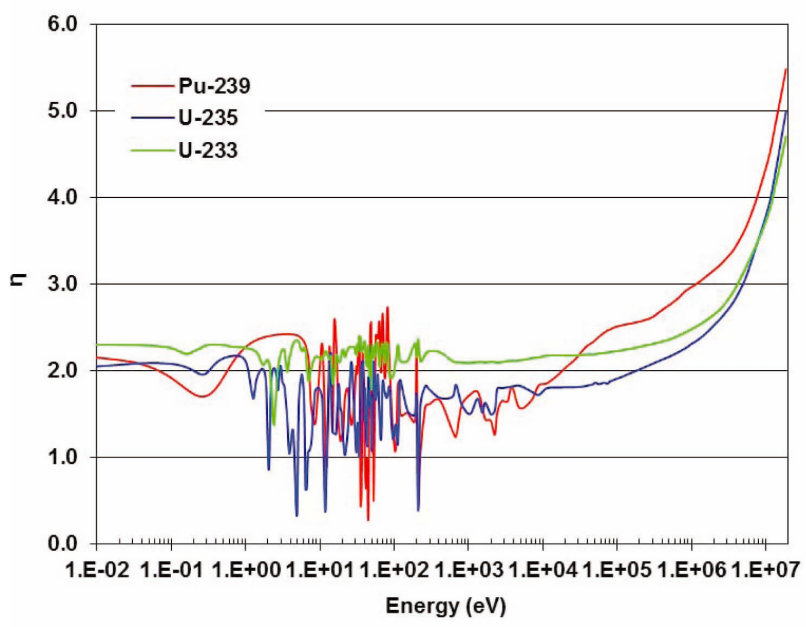

Fig. 1. $\eta(E)$ of Fissile Isotopes
${ }^{239} \mathrm{Pu}$ can be bred if the average energy of neutron spectrum is higher than $\sim 100 \mathrm{keV}$. It is seen that ${ }^{239} \mathrm{Pu}$ is preferred over ${ }^{233} \mathrm{U}$ in the fast energy region because of its higher value of $\eta$.

The breeding capability of a reactor is represented by the doubling time defined as the time interval during which the amount of fissile material in (or associated with) a reactor doubles. To minimize the doubling time, it is needed to maximize the breeding ratio and minimize the critical fissile inventory. As shown in Fig. 1, $\eta(E)$ increases rapidly with increasing energy. A harder spectrum also yields a higher fertile fission bonus $\varepsilon$ since fission of a fertile material is possible only for incident neutrons above some threshold. As a result, the breeding ratio increases with increasingly harder neutron spectrum. Spectrum hardening is controlled by the heavy atom density (relative to coolant and structure atom densities). A high heavy atom density is achieved by a high density fuel and a high fuel volume fraction. A tight triangular lattice is normally used to maximize the fuel volume fraction within the heat removal constraint. It is also noted that the critical fissile inventory decreases with increasing fuel volume fraction.

As an example, the breeding ratio components of oxide, carbide and metal fueled SFRs, taken from Ref. 11, are compared in Table 1. In proportion to the heavy metal density, the neutron spectrum is harder in the order of oxide, carbide, and metal fuels. The total neutron excess is about 14 points higher for carbide and 32 points higher for metal fuel than for oxide fuel. About one-half of the increment is due to the increase in $\eta$ values of fissile

Table 1. Comparison of Breeding Ratio Components between Oxide, Carbide, and Metal Fueled SFRs for Pu/U Cycle

\begin{tabular}{l|c|c|c}
\hline \multirow{2}{*}{$\eta$ of Fissile Isotopes } & Oxide & Carbide & Metal \\
\hline Fertile Fission Bonus, $\varepsilon$ & 2.283 & 2.353 & 2.450 \\
\hline$\eta-1+\varepsilon$ & 0.356 & 0.429 & 0.509 \\
\hline Neutron Loss & 1.639 & 1.782 & 1.959 \\
\hline \multirow{2}{*}{$\begin{array}{c}\text { Absorption Loss } \\
\text { Structure }\end{array}$} & 0.308 & 0.279 & 0.332 \\
\cline { 2 - 4 } Coolant & 0.231 & 0.199 & 0.218 \\
\cline { 2 - 4 } $\begin{array}{c}\text { Fission Products } \\
\text { O, C, or Zr }\end{array}$ & 0.158 & 0.131 & 0.127 \\
\cline { 2 - 4 } & 0.010 & 0.009 & 0.008 \\
\cline { 2 - 4 } Leakage Loss & 0.008 & 0.001 & 0.025 \\
\hline Pu-241 Decay Loss & 0.046 & 0.051 & 0.082 \\
\hline Net Neutrons for Breeding & 1.331 & 1.503 & 1.627 \\
\hline
\end{tabular}


isotopes and the other half is the increase in fertile fission bonus as the spectrum hardens. Absorption in the structural material contributes $60-70 \%$ of the total absorption losses, the fission products contribute about $25 \%$, and absorption losses due to the coolant and fuel diluent constituents are negligible. The variations in the absorption losses between oxide, carbide, and metal are relatively small, resulting in only 2-3 point differences in the breeding ratio. The leakage loss is higher for the metal fuel core because of the harder neutron spectrum and the smaller core configuration, compared to either oxide or carbide fuel core.

\subsection{Actinide Transmutation Capability}

Figure 2 shows the fission cross sections of ${ }^{235} \mathrm{U},{ }^{238} \mathrm{U}$, ${ }^{239} \mathrm{Pu}$ and ${ }^{241} \mathrm{Pu}$ in the ENDF/B-VII.0 libraries. As shown in these examples, the fission cross sections of fissile isotopes show relatively flat energy variations above the resonance region. The fission cross sections of fertile isotopes are also rather flat above threshold energies. On the other hand, the capture cross section decreases sharply in fast neutron region for both fissile and fertile isotopes, as shown in Fig. 3. As a result, the fission-to-capture ratio increases rapidly in fast neutron region.

Table 2 shows the fission-to-absorption ratios of major actinides in typical PWR (pressurized water reactor) and SFR systems. As can be seen, fissile isotopes are likely to fission in both thermal and fast spectrum systems, with higher fission fractions in the fast system. However, fertile isotopes have very small fission probabilities in the thermal system, and thus they are transmuted into higher actinides instead of being destroyed by fission. In the fast system, the fission probabilities of fertile isotopes increase significantly (up to $\sim 60 \%$ ), and more excess neutrons are produced. As a result, transuranic elements can be consumed efficiently with less generation of higher actinides.

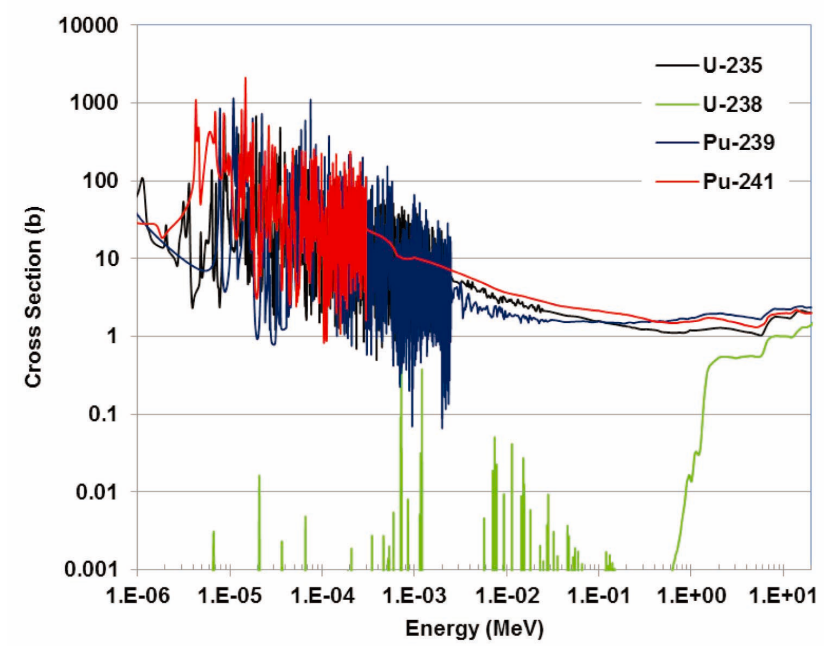

Fig. 2. Fission Cross Sections of ${ }^{235} \mathrm{U},{ }^{238} \mathrm{U},{ }^{239} \mathrm{Pu}$ and ${ }^{241} \mathrm{Pu}$

\subsection{Slowing-Down Properties and Flux Spectrum}

Figure 4 compares the elastic scattering cross sections of ${ }^{23} \mathrm{Na},{ }^{56} \mathrm{Fe}$ and ${ }^{238} \mathrm{U}$ with that of ${ }^{1} \mathrm{H}$ in the ENDF/B-VII libraries. The scattering cross sections of main constituent materials of SFR are comparable to that of hydrogen. This indicates that neutrons can undergo significant elastic

Table 2. Actinides Fission-to-Absorption Ratios in Thermal (PWR) and Fast (SFR) Systems

\begin{tabular}{c|c|c}
\hline Isotope & PWR & SFR \\
\hline $\mathrm{U}-235$ & 0.821 & 0.807 \\
\hline $\mathrm{U}-238$ & 0.099 & 0.194 \\
\hline $\mathrm{Np}-237$ & 0.014 & 0.296 \\
\hline $\mathrm{Pu}-238$ & 0.072 & 0.711 \\
\hline $\mathrm{Pu}-239$ & 0.637 & 0.865 \\
\hline $\mathrm{Pu}-240$ & 0.003 & 0.576 \\
\hline $\mathrm{Pu}-241$ & 0.747 & 0.873 \\
\hline $\mathrm{Pu}-242$ & 0.015 & 0.550 \\
\hline $\mathrm{Am}-241$ & 0.011 & 0.233 \\
\hline $\mathrm{Am}-242 \mathrm{~m}$ & 0.812 & 0.870 \\
\hline $\mathrm{Am}-243$ & 0.008 & 0.334 \\
\hline $\mathrm{Cm}-242$ & 0.212 & 0.579 \\
\hline $\mathrm{Cm}-243$ & 0.847 & 0.943 \\
\hline $\mathrm{Cm}-244$ & 0.054 & 0.479 \\
\hline $\mathrm{Cm}-245$ & 0.865 & 0.914 \\
\hline
\end{tabular}

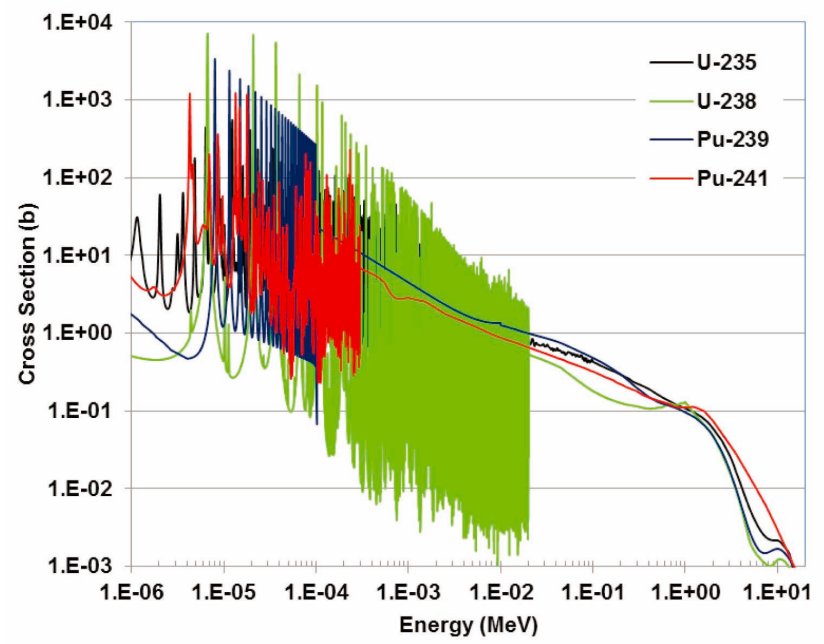

Fig. 3. Capture Cross Sections of ${ }^{235} \mathrm{U},{ }^{238} \mathrm{U},{ }^{239} \mathrm{Pu}$ and ${ }^{241} \mathrm{Pu}$ 
scattering even in fast energy region and thus moderation should be minimized by avoiding the use of low atomic mass nuclides that cause large neutron energy losses for elastic scattering. It is also noted that intermediate weight nuclei such as ${ }^{23} \mathrm{Na}$ and ${ }^{56} \mathrm{Fe}$ have significant scattering resonance structures throughout the fast energy range. Table 3 compares the slowing-down properties of main constituent materials of SFR with that of hydrogen in PWR. It can be seen that the slowing-down power in SFR is only $\sim 1 \%$ or so of that observed for a typical PWR. Thus, neutrons are either absorbed or leak out from the core before they can reach thermal energies. The angular distribution of elastic scattering becomes more peaked in the forward direction with increasing incident neutron energy. At high energies, therefore, the average cosine of scattering angle

Table 3. Slowing-Down Properties of Major Constituent Materials of SFR

\begin{tabular}{c|c|c|c}
\hline & $\begin{array}{c}\text { Scattering cross } \\
\text { section, } \sigma_{\mathrm{s}}(\mathrm{b})\end{array}$ & $\begin{array}{c}\text { Atom density } \\
(/ \mathrm{barn} \cdot \mathrm{cm})\end{array}$ & $\begin{array}{c}\text { Slowing-down } \\
\text { power, } \xi \Sigma_{\mathrm{s}}\left(\mathrm{cm}^{-1}\right)\end{array}$ \\
\hline \multirow{2}{*}{$\mathrm{TRU}$} & 4.0 & $3.2 \mathrm{E}-03$ & $1.1 \mathrm{E}-04$ \\
\cline { 2 - 4 } $\mathrm{U}$ & 5.6 & $5.6 \mathrm{E}-03$ & $2.7 \mathrm{E}-04$ \\
\cline { 2 - 4 } $\mathrm{Zr}$ & 8.1 & $2.6 \mathrm{E}-03$ & $4.6 \mathrm{E}-04$ \\
\cline { 2 - 4 } $\mathrm{Fe}$ & 3.4 & $1.9 \mathrm{E}-02$ & $2.3 \mathrm{E}-03$ \\
\cline { 2 - 4 } $\mathrm{Na}$ & 3.8 & $8.2 \mathrm{E}-03$ & $2.7 \mathrm{E}-03$ \\
\cline { 2 - 4 } $\mathrm{O}$ & 3.6 & $1.4 \mathrm{E}-02$ & $5.8 \mathrm{E}-03$ \\
\hline $\mathrm{H}^{*}$ & 11.9 & $2.9 \mathrm{E}-02$ & $3.5 \mathrm{E}-01$ \\
\hline
\end{tabular}

${ }^{*}$ Typical values in PWR

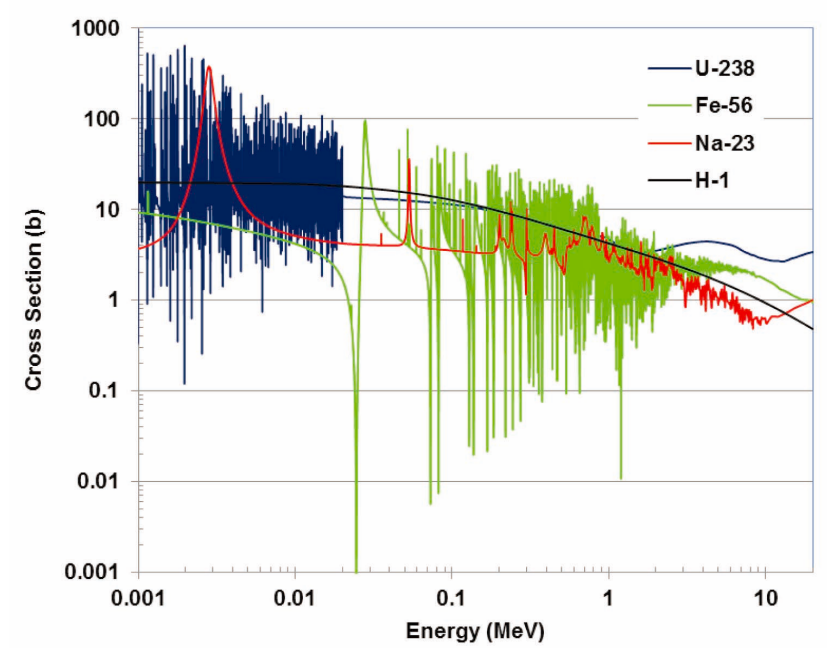

Fig. 4. Elastic Scattering Cross Sections of ${ }^{23} \mathrm{Na},{ }^{56} \mathrm{Fe},{ }^{238} \mathrm{U}$ and ${ }^{239} \mathrm{Pu}$ approaches unity, which causes transport cross sections decreases and enhance high-energy leakage.

The threshold energy for inelastic scattering decreases with increasing atomic mass number, and inelastic scattering causes neutrons to lose substantial energy. By comparing the inelastic scattering cross sections in Fig. 5 with the elastic scattering cross sections in Fig. 4, it can be seen that above the threshold energy, inelastic scattering cross section is comparable to elastic scattering cross section. Therefore, inelastic scattering plays an important role in fast reactors, being the major cause of neutron moderation at high energies. Inelastic scattering in sodium also makes an important contribution to the sodium void effect. It is noted that $(\mathrm{n}, 2 \mathrm{n})$ reactions are not negligible as indicated by the $(\mathrm{n}, 2 \mathrm{n})$ cross sections shown in Fig. 6 .

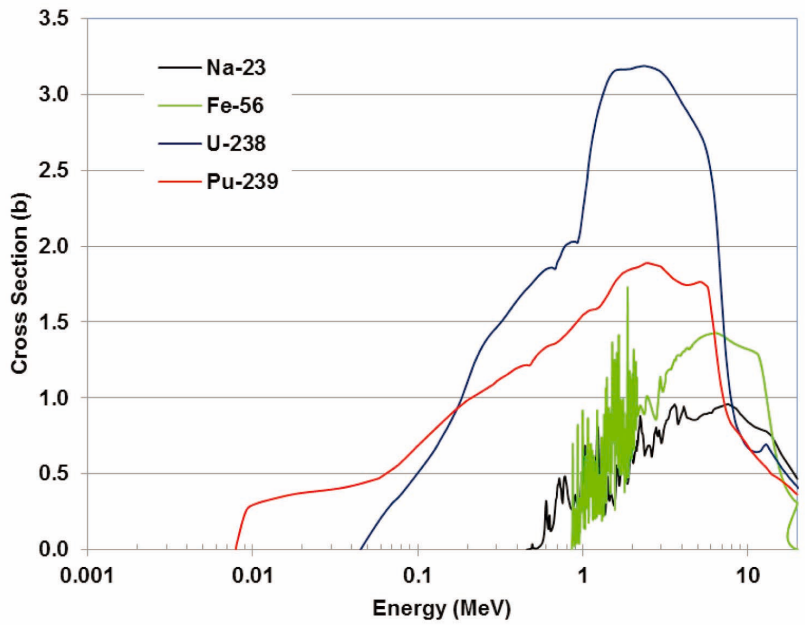

Fig. 5. Inelastic Scattering Cross Sections of ${ }^{23} \mathrm{Na},{ }^{56} \mathrm{Fe},{ }^{238} \mathrm{U}$ and ${ }^{239} \mathrm{Pu}$

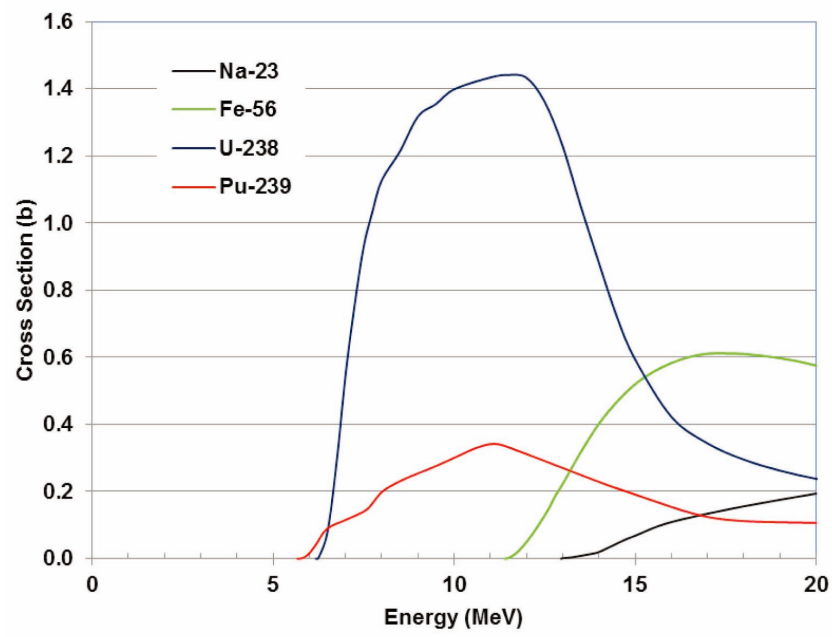

Fig. 6. (n,2n) Cross Sections of ${ }^{23} \mathrm{Na},{ }^{56} \mathrm{Fe},{ }^{238} \mathrm{U}$ and ${ }^{239} \mathrm{Pu}$ 


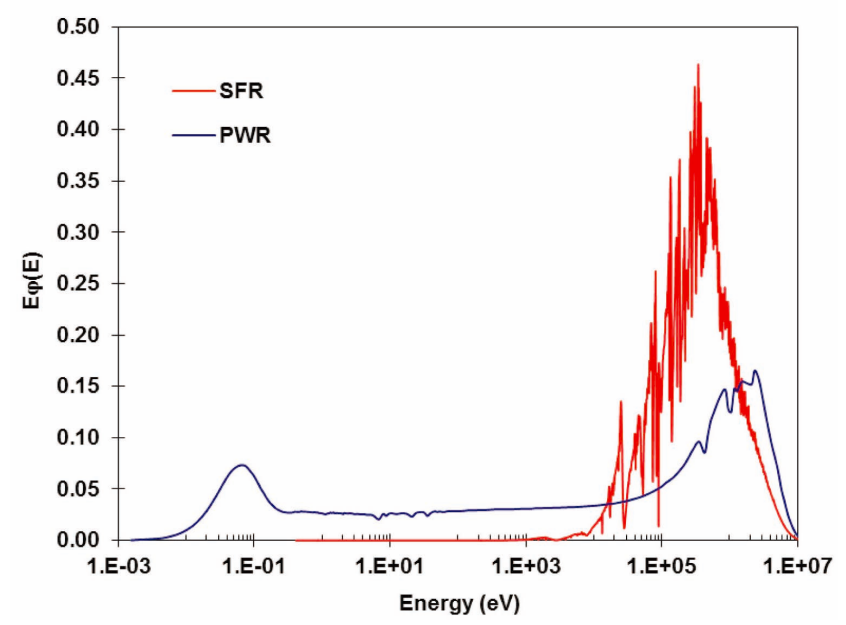

Fig. 7. Neutron Flux Spectra of Thermal (PWR) and Fast (SFR) Reactors

Figure 7 compares typical neutron spectra for SFR and PWR. In fast reactors, the small slowing down power results in a flux spectrum concentrated in the $\mathrm{keV}$ and $\mathrm{MeV}$ range with almost no neutrons slowing down to energies less than $1 \mathrm{keV}$. As a result, the energy range where neutrons induce fission and the energy range where the fission neutrons appear strongly overlap, whereas in thermal reactors most fission occurs in the thermal peak. The scattering resonances of intermediate atomic weight nuclides (sodium, oxygen in the case of oxide fuel, and structural materials like iron, chro-mium, nickel, etc.) give rise to the strongly jagged structure of fast reactor spectrum, resulting from the energy self-shielding phenomenon, in which the flux is inversely proportional to the total cross section. The $1 / \mathrm{E}$ [or constant $\mathrm{E} \varphi(\mathrm{E})]$ spectrum of thermal reactors in the heavy isotope resonance region, which is used as a basis for the calculation of resonance absorption, is lacking in fast reactors; in fact, $\mathrm{E} \varphi(\mathrm{E})$ strongly decreases with decreasing energy.

\subsection{Core Design and Performance Implications}

For conventional FBRs, to increase the breeding ratio and to reduce the fissile inventory, compact core designs are used along with tightly packed pin lattices. As a result, they have a high power density and require very efficient heat transfer. All the fast reactors built by this time are liquid metal cooled reactors. Mercury was used for Clementine and BR-1, and NaK was used for EBR-I and DFR (Dounreay Fast Reactor) because of the low melting point. [12] Lead-cooled fast reactors (LFR) were used in Russian naval propulsion units as well as some other prototype reactors. All large-scale fast reactors have used molten sodium coolant. [13] Gas-cooled fast reactors (GFR) have been the subject of research as well, but never been built. Because of small capture cross sections in fast region, conventional stainless steels are normally used as the structural material. The fuel and blanket pins are clad in stainless steel tubes, to form the fuel and blanket elements, which have wire wrapping or a grid support to provide channels for coolant flow.

In order to enhance the breeding ratio by minimizing the neutron leakage loss and by introducing additional fertile material, high fuel volume fraction blankets are also employed. The external breeding configuration was used for early small FBRs by containing all the fertile material in the blanket surrounding the core. Such an arrangement yields a very hard spectrum, a low fissile inventory, and a good breeding ratio. However, the lack of in-core breeding results in a rapid reactivity loss with burnup, a small Doppler effect and few fast fissions in fertile material, and requires a high fissile enrichment and a thick blanket. Subsequent designs allowed for considerable internal or in-core breeding by mixing some fertile fuel with fissile fuel within the core fuel assemblies; they normally have an in-core breeding ratio less than one, but the breeding in the surrounding blankets raises the total breeding ratio to well in excess of unity. Homogeneous core designs were initially employed by locating all blanket assemblies containing pure fertile fuel in the radial and axial blanket regions. This leaves a relatively homogeneous mixture of fissile and fertile fuel spread throughout the core. Heterogeneous core configurations were introduced later by distributing blanket assemblies through the core region. These designs yield higher breeding ratios and reduced sodium void coefficients, but require higher fissile fuel inventories.

The primary mission of burner reactors is to transmute the TRU elements recovered from light water reactor (LWR) used fuel, and hence to realize the benefits of the fuel cycle closure to nuclear waste management. [14,15] To achieve a high TRU consumption rate, it is desirable to have a low TRU conversion ratio. Here, the TRU conversion ratio is defined as the average number of all TRU (rather than fissile) nuclides produced in a reactor per TRU nuclide consumed. Since fission of one gram TRU produces about one MWD energy, the TRU consumption rate is determined by the reactor power rating. Thus the TRU conversion ratio is minimized by minimizing the TRU production rate. Theoretically the TRU conversion ratio can be reduced to zero by removing all fertile blankets and utilizing a uranium-free fuel. However, the neutronics properties of uranium-free fuel make it very difficult, if not impossible, to achieve a TRU conversion ratio of zero. In particular, the Doppler feedback coefficient of uranium-free fuel is almost zero or becomes slightly positive, depending on fuel compositions, and the delayed neutron fraction is reduced significantly. Furthermore, uranium-free solid fuels would need a significant development time.

To reduce the TRU conversion ratio, it is necessary to increase the TRU faction in heavy metal, which in turn 


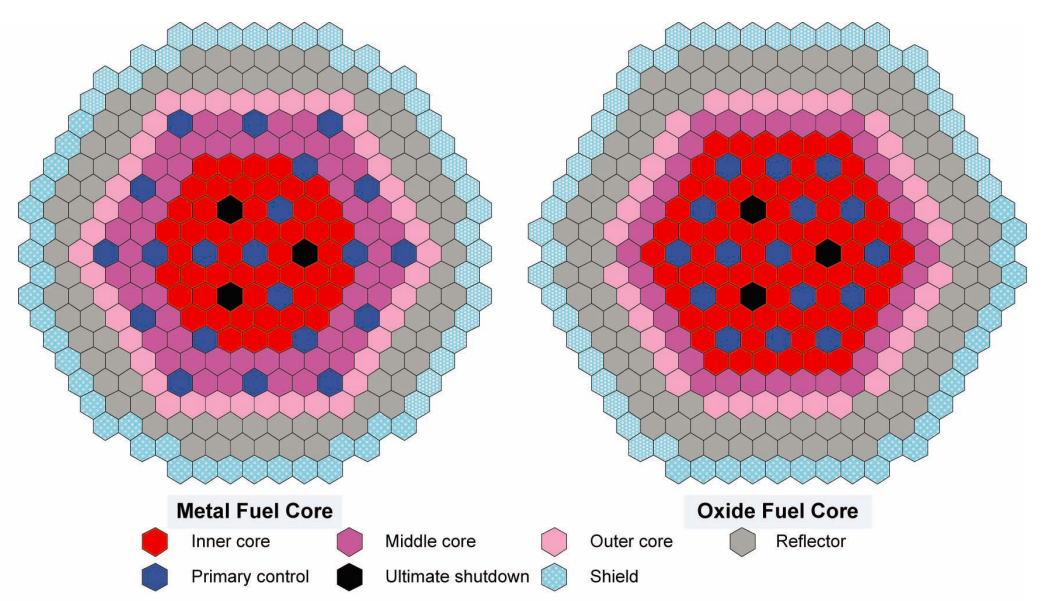

Fig. 8. Metal and Oxide Core Layouts for TRU Conversion Ratio of 0.25

requires reducing the fuel volume fraction. The increasing burnup reactivity loss with decreasing TRU conversion ratio should also be compensated for either by increasing the number of control assemblies or by reducing the cycle length. A recent study on advanced burner reactor (ABR) showed that the TRU consumption rate reaches $\sim 80 \%$ of the maximum theoretical value when the TRU conversion ratio is in the range of $0.25-0.35$. [16] Using ternary metal and mixed oxide fuels, ABR core concepts of $1000 \mathrm{MWt}$ power rating were developed for target TRU conversion ratios of $1.0,0.75,0.50,0.25$, and 0.0 . Two makeup TRU feeds were considered with minor actinides (MA) to plutonium ratios of 0.1 and 1.0. To compensate for the increasing burnup reactivity swing, the number of primary control assemblies was increased for low conversion ratio cores. Example metal and oxide core layouts are shown in Fig. 8 for the TRU conversion ratio of 0.25 . The fuel cycle length was also adjusted such that the burnup reactivity swing is within the reactivity control capability of the primary control system. The resulting TRU fraction in heavy metal was $\sim 50$ to $\sim 75 \%$, depending on the fuel type and makeup TRU feed stream. The estimated safety parameters indicated that the metal and oxide cores of TRU conversion ratio in the range of $0.25-0.40$ are feasible with favorable passive safety features. The safety parameters of these cores were comparable to those of conventional fast reactor cores that have already been proven to be feasible, and the sufficient conditions for acceptable asymptotic core outlet temperatures for possible unprotected accident scenarios are satisfied. A detailed safety study for a compact fast burner reactor of $840 \mathrm{MWt}$ power rating also showed that a reactor design with a TRU conversion ratio of 0.25 responds to the unprotected lossof-flow (ULOF) accident with a very high level of selfprotection. [17]
Table 4. Typical Material Volume Fractions (\%) of Fast and Thermal Systems

\begin{tabular}{l|c|c|c|c}
\hline \multicolumn{2}{c|}{ Material } & Fuel & Coolant & Structure \\
\hline \multirow{2}{*}{ SFR } & $\mathrm{CR}=1.0$ & 40 & 35 & 25 \\
\cline { 2 - 5 } & $\mathrm{CR}=0.5$ & 30 & 44 & 26 \\
\hline \multirow{2}{*}{ LFR } & 34 & 55 & 11 \\
\hline GFR & 30 & 57 & 13 \\
\hline \multicolumn{2}{l|}{ PWR } & 30 & 59 & 11 \\
\hline
\end{tabular}

Table 4 compares typical material volume fractions of SFR, LFR, GFR and PWR. For SFR, a breakeven core and a burner core with TRU conversion ratios of 1 and 0.5 , respectively, are considered. Compared to the breakeven core, the burner design uses smaller fuel pins to lower the fuel volume fraction needed to reduce TRU production and to yield an increased coolant volume fraction. Because of the hexagonal steel tube containing fuel pins, SFR has a significantly larger structure volume fraction than the other reactor types. With lead-based coolant, corrosion and erosive wear of core structural materials are intensified as coolant velocity increases. Therefore a higher coolant volume fraction is used in LFR to reduce coolant velocity for both oxygen control and reasonable pumping power. For GFR, a higher coolant volume fraction is required because of inferior heat transfer properties of helium coolant. It is determined by trade-off between pumping power and neutronics performance.

Compared to thermal reactors, fast reactors require much higher fissile fractions to achieve criticality. The reason for this is that ${ }^{238} \mathrm{U}$ capture is much more prominent 
in fast reactors. As shown in Fig. 9, the ratio of ${ }^{239} \mathrm{Pu}$ or ${ }^{235} \mathrm{U}$ fission cross section to ${ }^{238} \mathrm{U}$ capture cross section is $\sim 200-300$ in thermal region but only $\sim 10$ in the tens and hundreds keV range in which most of SFR spectrum is. As a result, it is impossible to build a fast reactor using only natural uranium fuel. Table 5 shows effective onegroup cross sections of a few important nuclides in PWR and five Generation-IV systems. It can be seen that the three fast systems have similar characteristics and that one-group cross sections are significantly reduced compared to thermal systems. The ratio between ${ }^{239} \mathrm{Pu}$ fission cross section and ${ }^{238} \mathrm{U}$ capture cross section is only $6-8$ in the three fast systems while it is $\sim 100$ in PWR. This necessitates a higher fissile fraction, but it also enhances internal conversion. Iron capture cross section is much smaller in fast systems, allowing the use of conventional steel structures. The reduced parasitic capture of fission products and the enhanced internal conversion in fast systems yield a slow loss of reactivity with burnup. Lower

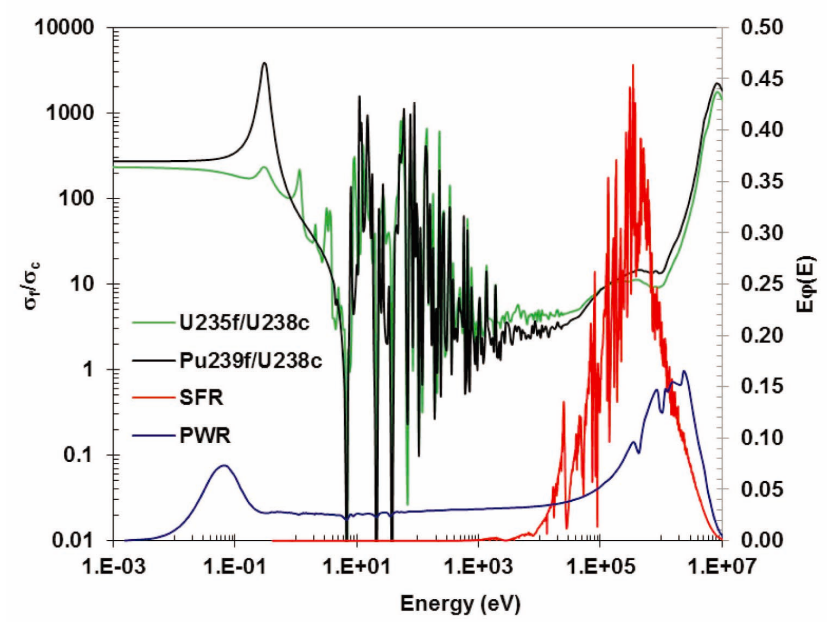

Fig. 9. Ratios of ${ }^{235} \mathrm{U}$ and ${ }^{239} \mathrm{Pu}$ Fission Cross Sections to ${ }^{238} \mathrm{U}$ Capture Cross Section absorption cross section of all materials in fast systems leads to a much longer neutron mean free path $(\sim 10 \mathrm{~cm}$ as compared to $\sim 1 \mathrm{~cm}$ in PWR), which increases the neutron leakage from the core (>20\% in typical designs). The increased leakage makes the reflector effects more pronounced in burner reactors. The long mean free path makes local heterogeneity effects less important (except for plate-type fuels in critical facilities) as indicated by the reactivity effects shown in Table 6 , taken from References 18 and 19. The long mean free path also implies global coupling of the core so that local reactivity effects may impact the entire core.

Table 7 compares the neutron balance components of two SFR cores to those of PWR. No blanket was used in the breakeven core as in the burner core. The TRU fraction in fuel is 3.3 times larger in the breakeven core and 7.9 times larger in the burner core than the ${ }^{235} \mathrm{U}$ enrichment of PWR fuel. It is noted that $(n, 2 n)$ source makes a nonnegligible contribution to the neutron production in SFR, whereas it is negligible in PWR. Compared to PWR, SFR cores have significantly larger leakage but smaller total absorption. The leakage is $3.5 \%$ in PWR, but it is increased to $\sim 23 \%$ in the breakeven core and to $\sim 29 \%$ in the burner core. The absorption in ${ }^{238} \mathrm{U}$ is $11 \%$ more in the breakeven core, but $6 \%$ smaller in the burner core than in PWR. The absorptions in coolant, fission products and reactivity control material are reduced significantly in SFR

Table 6. Local Heterogeneity Effects on Reactivity in Fast Reactors

\begin{tabular}{c|c|c|c|c}
\hline \multicolumn{2}{c|}{ Component } & Non-Leakage & Streaming & Total \\
\hline ZEBRA, & Pin & $0.49 \%$ & $-0.11 \%$ & $0.38 \%$ \\
\cline { 2 - 5 } CADENZA & Plate & $1.54 \%$ & $-0.16 \%$ & $1.38 \%$ \\
\hline SuperPhénix & $0.71 \%$ & $-0.20 \%$ & $0.51 \%$ \\
\hline \multicolumn{2}{c}{ ABTR } & & & $0.34 \%$ \\
\hline
\end{tabular}

Table 5. Effective One-Group Cross Sections (barns) of PWR and Generation IV Systems

\begin{tabular}{c|c|c|c|c|c|c}
\hline \multirow{2}{*}{ Reaction } & \multicolumn{3}{|c|}{ Thermal Concepts } & \multicolumn{3}{c}{ Fast Concepts } \\
\cline { 2 - 7 } & PWR & VHTR & SCWR & SFR & LFR & GFR \\
\hline${ }^{238} \mathrm{U}$ capture $\left(\sigma_{c}^{28}\right)$ & 0.91 & 4.80 & 0.95 & 0.20 & 0.26 & 0.32 \\
\hline${ }^{239} \mathrm{Pu}$ fission $\left(\sigma_{f}^{49}\right)$ & 89.2 & 164.5 & 138.8 & 1.65 & 1.69 & 6.59 \\
\hline$\sigma_{f}^{49} / \sigma_{c}^{28}$ & 97.7 & 34.3 & 146.6 & 8.14 & & 6.00 \\
\hline Fe capture & 0.4 & & & 0.007 & & \\
\hline LFP capture & 90 & & & 0.2 & & \\
\hline
\end{tabular}

${ }^{*}$ LFP: lumped fission product 
cores, but the absorption in structure increases noticeably because of much larger structure volume fraction in SFR fuel assemblies. Compared to the breakeven core, the burner core has 2.4 times higher TRU fraction, which results in the reduced absorption in ${ }^{238} \mathrm{U}$ by $50 \%$. The reduced absorption in ${ }^{238} \mathrm{U}$ is primarily balanced by the increased leakage and increased absorption in control material.

\subsection{Kinetics Parameters and Reactivity Feedback Effects}

The reactivity feedback coefficients and kinetic parameters further define the physics of system, although they are used only for the conventional point kinetics or quasi-static kinetics models. (Space-dependent kinetics models directly use the variations of cross sections and those of geometric and material configurations.) [20] They are computed for specific geometric and material configurations by the response to a variety of perturbations. A typical set of computed kinetic parameters and reactivity coefficients includes the delayed neutron fraction and prompt neutron lifetime, the coolant density coefficient and void worth, the fuel and structural material Doppler coefficients, the fuel and structural material worth distributions, the axial expansion coefficient, the radial core expansion coefficient, and the control rod driveline expansion coefficient. The coolant, fuel, and structural material density coefficients and the coolant void worth

Table 7. Comparison of Neutron Balance Components in SFR and PWR

\begin{tabular}{|c|c|c|c|c|}
\hline & \multirow{2}{*}{ Reactor } & \multicolumn{2}{|c|}{ SFR } & \multirow{2}{*}{ PWR } \\
\hline & & $\mathrm{CR}=1.0$ & $\mathrm{CR}=0.5$ & \\
\hline \multicolumn{2}{|c|}{${ }^{235} \mathrm{U}$ or TRU fraction, $\%$} & 13.9 & 33.3 & 4.2 \\
\hline \multirow{2}{*}{ Source } & Fission & 99.8 & 99.9 & 100.0 \\
\hline & $(\mathrm{n}, 2 \mathrm{n})$ & 0.2 & 0.1 & \\
\hline \multirow{10}{*}{ Loss } & Leakage & 22.9 & 28.7 & 3.5 \\
\hline & Radial & 12.3 & 16.6 & 3.0 \\
\hline & Axial & 10.6 & 12.1 & 0.4 \\
\hline & \multirow{3}{*}{$\begin{array}{l}\text { Absorption } \\
{ }^{235} \mathrm{U} \text { or TRU } \\
{ }^{238} \mathrm{U}\end{array}$} & 77.1 & 71.3 & 96.5 \\
\hline & & 37.0 & 44.3 & 52.8 \\
\hline & & 34.8 & 17.7 & 23.9 \\
\hline & \multirow{4}{*}{$\begin{array}{l}\text { Coolant } \\
\text { Structure } \\
\text { Fission products } \\
\text { Control }\end{array}$} & 0.1 & 0.1 & 3.4 \\
\hline & & 3.7 & 3.7 & 0.6 \\
\hline & & 1.5 & 2.4 & 6.8 \\
\hline & & 0.0 & 2.9 & 9.0 \\
\hline
\end{tabular}

are usually determined using the perturbation theory method. The first order perturbation theory is used for density coefficients, while the exact perturbation theory is employed for the coolant void worth. The effective delayed neutron fraction and prompt neutron lifetime are also calculated using the perturbation theory method. The radial and axial expansion coefficients and the control rod driveline expansion coefficient are typically determined by direct eigenvalue differences of the base and perturbed configurations. It is noted that the role of specific reactivity coefficients varies markedly depending on the transient. For example, the usually desirable negative Doppler coefficient can play an adverse role in loss-of-flow accidents, in which the fuel temperature decreases as the power goes down faster than the heat flux. References 21 and 22 provide good discussions on the reactivity feedback coefficients and on the system disturbances and feedback mechanisms in fast reactors.

The delayed neutron fraction and prompt neutron lifetime are indicators of the system sensitivity to reactivity changes. At low values, the response to small changes in the reactivity is magnified and power can change more quickly. Table 8 shows the delayed neutron fractions of fissionable isotopes in the ENDF/B-VII data at two incident neutron energies. As can be seen, it is significantly different for different fissionable isotopes. The delayed neutron fraction decreases with increasing atomic number, and for a given element, it increases with increasing atomic
Table 8. Delayed Neutron Fraction of Fissionable Isotopes

\begin{tabular}{c|c|c}
\hline Isotope & $\begin{array}{c}\text { Thermal } \\
(0.1 \mathrm{eV})\end{array}$ & $\begin{array}{c}\text { Fast } \\
(350 \mathrm{keV})\end{array}$ \\
\hline $\mathrm{U}-235$ & 0.00651 & 0.00674 \\
\hline $\mathrm{U}-238$ & 0.01766 & 0.01748 \\
\hline $\mathrm{Np}-237$ & 0.00410 & 0.00402 \\
\hline $\mathrm{Pu}-238$ & 0.00144 & 0.00142 \\
\hline $\mathrm{Pu}-239$ & 0.00225 & 0.00220 \\
\hline $\mathrm{Pu}-240$ & 0.00321 & 0.00315 \\
\hline $\mathrm{Pu}-241$ & 0.00550 & 0.00550 \\
\hline $\mathrm{Pu}-242$ & 0.00701 & 0.00688 \\
\hline $\mathrm{Am}-241$ & 0.00139 & 0.00136 \\
\hline $\mathrm{Am}-242 \mathrm{~m}$ & 0.00199 & 0.00196 \\
\hline $\mathrm{Am}-243$ & 0.00243 & 0.00239 \\
\hline $\mathrm{Cm}-243$ & 0.00088 & 0.00087 \\
\hline $\mathrm{Cm}-244$ & 0.00134 & 0.00132 \\
\hline $\mathrm{Cm}-245$ & 0.00178 & 0.00178 \\
\hline
\end{tabular}


weight. It is high $(\sim 1.8 \%)$ for ${ }^{238} \mathrm{U}$ but low $(\sim 0.2 \%)$ for ${ }^{239} \mathrm{Pu}$. It varies between $0.3-0.7 \%$ for higher plutonium isotopes, and it becomes particularly low for minor actinides. In a reactor, the effective delayed neutron fraction is determined by key fission isotopes. As shown in Table 9, in fast reactors fueled with $\mathrm{Pu}$ or TRU, the contributions of ${ }^{238} \mathrm{U},{ }^{240} \mathrm{Pu}$ and ${ }^{241} \mathrm{Pu}$ fissions are significant. Therefore, in a conventional breeder reactor, it becomes $0.3-0.4 \%$, being significantly larger than $0.2 \%$ of the main fissile isotope ${ }^{239} \mathrm{Pu}$. In burner reactors, in order to enhance the TRU destruction rate, ${ }^{238} \mathrm{U}$ loading is reduced by increasing the critical TRU fraction through reduced fuel volume fraction. Table 10 shows the delayed neutron fraction and prompt neutron lifetime for different TRU conversion ratios. As the TRU conversion ratio decreases, the heavy metal (HM) inventory decreases but the TRU fraction in HM increases; the effective delayed neutron fraction decreases due to reduced ${ }^{238} \mathrm{U}$ fission, but the prompt neutron lifetime increases due to reduced absorption in HM.

The Doppler broadening of resonance cross sections reduces the resonance self-shielding with increasing temperature, yielding the increase in effective cross sections. The net reactivity effect arises from a varying competition of fission, capture, and leakage processes, and its importance for safety lies in its provision of a prompt negative reactivity effect from fuel heating. A positive Doppler effect was a concern for early small reactors with a high concentration

Table 9. Isotopic Fission Fractions (\%) in SFR and PWR

\begin{tabular}{|c|c|c|c|}
\hline \multirow{2}{*}{ Reactor } & \multicolumn{2}{|c|}{ SFR } & \multirow{2}{*}{ PWR } \\
\hline & $\mathrm{CR}=1.0$ & $\mathrm{CR}=0.5$ & \\
\hline U-235 or TRU fraction, $\%$ & 13.9 & 33.3 & 4.2 \\
\hline $\mathrm{U}-235$ & 0.2 & 0.2 & 59.8 \\
\hline U-238 & 15.7 & 8.3 & 6.2 \\
\hline $\mathrm{Np}-237$ & 0.2 & 0.6 & \\
\hline $\mathrm{Pu}-238$ & 0.8 & 3.4 & \\
\hline Pu-239 & 70.7 & 57.0 & 29.8 \\
\hline $\mathrm{Pu}-240$ & 6.7 & 11.4 & \\
\hline $\mathrm{Pu}-241$ & 4.5 & 11.9 & 4.0 \\
\hline $\mathrm{Pu}-242$ & 0.4 & 2.5 & \\
\hline Am241 & 0.3 & 0.8 & \\
\hline Am-242m & 0.2 & 0.6 & \\
\hline Am-243 & 0.1 & 0.7 & \\
\hline $\mathrm{Cm}-244$ & 0.1 & 0.9 & \\
\hline $\mathrm{Cm}-245$ & 0.1 & 1.2 & \\
\hline
\end{tabular}

of fissile material. The negative Doppler coefficient in large FBRs with a high fertile-to-fissile ratio arises primarily from ${ }^{238} \mathrm{U}$ resonance broadening and is enhanced by high ${ }^{238} \mathrm{U}$ content. Since the self-shielding effect is more pronounced at low energies (in keV range), spectral softening enhances the Doppler effect and the sodium voiding results in smaller Doppler coefficient through spectral hardening. The temperature variation of Doppler coefficient is approximately $T^{1}$ for typical fast reactors, so the Doppler coefficient is often quoted in terms of the Doppler constant, $T(d \rho / d T)$. There is also a structural Doppler effect, which amounts to $\sim 1 / 3$ of the Doppler effect of fuel, but it is tied to the temperature of structure with different time constant. In TRU burner reactors, the reduced ${ }^{238} \mathrm{U}$ fraction makes the Doppler constant less negative as the TRU conversion ratio decreases, as shown in Figure 10. It is noted that the Doppler constant of the uranium-free core (i.e., CR 0.0) fueled with TRU feed of $\mathrm{MA} / \mathrm{Pu} \cong 1$ is almost zero for the metal core and slightly positive for the oxide core. As mentioned above, the Doppler feedback is not helpful in all transients. For

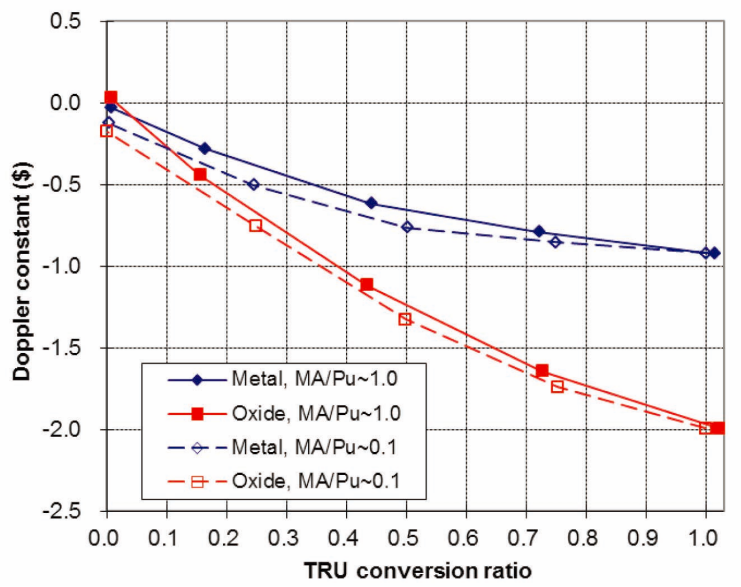

Fig. 10. Doppler Constant vs. TRU Conversion Ratio

Table 10. Effective Delayed Neutron Fraction and Prompt Neutron Lifetime vs. TRU Conversion Ratio (Metal Fuel, $\mathrm{MA} / \mathrm{Pu} \cong 0.1$ )

\begin{tabular}{c|c|c|c}
\hline $\begin{array}{c}\text { Conversion } \\
\text { Ratio }\end{array}$ & $\begin{array}{c}\text { TRU/HM } \\
(\%)\end{array}$ & $\begin{array}{c}\text { Delayed } \\
\text { Neutron Fraction }\end{array}$ & $\begin{array}{c}\text { Prompt Neutron } \\
\text { Lifetime }(\mu \mathrm{s})\end{array}$ \\
\hline 1.00 & 13.9 & 0.00353 & 0.299 \\
\hline 0.75 & 21.2 & 0.00329 & 0.325 \\
\hline 0.50 & 33.3 & 0.00301 & 0.382 \\
\hline 0.25 & 55.5 & 0.00273 & 0.448 \\
\hline 0.00 & 98.6 & 0.00245 & 0.538 \\
\hline
\end{tabular}


example, when trying to cool the fuel to shutdown condition in ULOF accidents, it provides a positive reactivity. Conversely it is a prompt negative feedback in unprotected transient over-power (UTOP) accidents.

The reactivity change that occurs when sodium density is reduced or voided from a reactor can be resolved into spectral, leakage, and capture components. The spectral effect results from the reduced moderation with decreasing sodium density, and it is a positive reactivity effect in fast regime because of increasing fissile $\eta$ and threshold fertile fission with increasing energy. Reduction in sodium density allows more neutron leakage and introduces a negative reactivity effect. A reduced sodium density also decreases the parasitic neutron capture in sodium and results in a positive reactivity effect, but this is a relatively minor effect. The spectral and capture components are normally at a maximum in the central part of the core, but the leakage component is high in the peripheral regions. The sodium density coefficient is generally computed by the first-order perturbation theory to evaluate the reactivity effects of small density variation due to temperature change. The sodium void worth is evaluated using the exact perturbation theory to account for the shift in flux distribution at voided condition. In general, the void worth is $\sim 10 \%$ more positive than the first-order density worth. The sodium density coefficient generally becomes more positive with decreasing TRU conversion ratio since the positive spectral effect over-weighs the negative leakage effect, but it does not show a monotonic behavior because of the variations in the core configuration, material volume fractions, and TRU inventory. As an example, Table 11 shows the sodium void worth by components for a $250 \mathrm{MWt}$ Advanced Burner Test Reactor (ABTR) design [14] and a 1000 MWt Advanced Burner Reactor (ABR) design [15]. These values were obtained by voiding the flowing sodium in the active core and above core regions. It can be seen that the spectral component becomes more positive and the leakage component becomes less negative with increasing core size. The net effect is positive for both ABTR and ABR and increases with increasing core size. However, it is difficult to conceive transient situations that reach sodium boiling since SFR is a low pressure system, the coolant has a more than $300{ }^{\circ} \mathrm{C}$ margin to boiling, and other feedbacks are negative, inhibiting temperature increase. Reference 23 provides an extensive report on void worth reduction.

Uniform axial and radial expansion coefficients are the reactivity change due to a small change in each dimension. Each of the expansion coefficients is actually the result of two components: the increased dimension and the correspondingly reduced material densities. The enlarged dimension itself tends to decrease the leakage, but the reduced material densities increase the leakage. The combined effect is an increased leakage, yielding a negative reactivity feedback. The radial expansion coefficient typically represents the reactivity effect due to the uniform expansion of the grid plate and the corresponding reduction of fuel and structure densities. The axial expansion coefficient is the reactivity effect due to the uniform axial expansion of fuel and the corresponding reduction of fuel density. The axial expansion of fuel also results in an effective insertion of control rods which remain stationary. Table 12 compares the neutron balances in the perturbed cases, in which the reactor radius and fuel height were increased by $1 \%$, respectively, with that in the unperturbed

Table 11. Sodium Void Worth by Components $(\$)$

\begin{tabular}{c|c|c|c|c|c}
\hline \multicolumn{2}{c|}{ Reactor } & Capture & Spectral & Leakage & Total \\
\hline $\begin{array}{c}250 \mathrm{MWt} \\
\text { ABTR }\end{array}$ & BOC & 0.4 & 6.4 & -5.8 & 1.0 \\
\cline { 2 - 6 } & EOC & 0.4 & 6.6 & -5.8 & 1.1 \\
\hline $\begin{array}{c}1000 \mathrm{MWt} \\
\text { ABR }\end{array}$ & BOC & 0.5 & 9.1 & -5.2 & 4.4 \\
\cline { 2 - 6 } & EOC & 0.5 & 9.9 & -5.5 & 4.9 \\
\hline
\end{tabular}

Table 12. Neutron Balances of Radial and Axial Expansions

\begin{tabular}{|c|c|c|c|c|c|}
\hline & \multirow{2}{*}{$\begin{array}{c}\text { Base Case } \\
\text { balance }\end{array}$} & \multicolumn{2}{|c|}{ Radial Expansion } & \multicolumn{2}{|c|}{ Axial Expansion } \\
\hline & & balance & $\Delta \rho(\%)$ & balance & $\Delta \rho(\%)$ \\
\hline Fission source & 100.00 & 100.00 & & 100.00 & \\
\hline$(n, 2 n)$ source & 0.18 & 0.18 & & 0.18 & \\
\hline Absorption & 68.89 & 68.93 & -0.04 & 69.06 & -0.17 \\
\hline Leakage & 31.54 & 32.16 & -0.63 & 31.69 & -0.16 \\
\hline Radial & 17.49 & 17.72 & -0.23 & 17.65 & -0.15 \\
\hline Axial & 14.05 & 14.45 & -0.40 & 14.04 & 0.01 \\
\hline Sum & & & -0.67 & & -0.33 \\
\hline
\end{tabular}


Table 13. Whole-Core Reactivity Coefficients vs. Core Size

\begin{tabular}{|c|c|c|c|c|}
\hline & unit & $\begin{array}{c}250 \mathrm{MWt} \\
\text { ABTR }\end{array}$ & $\begin{array}{c}1000 \mathrm{MWt} \\
\mathrm{ABR}\end{array}$ & $\begin{array}{c}3500 \mathrm{MWt} \\
\text { SFR }\end{array}$ \\
\hline Effective delayed neutron fraction & & 0.0033 & 0.0033 & 0.0035 \\
\hline Prompt neutron lifetime & $\mu_{\mathrm{s}}$ & 0.33 & 0.38 & 0.32 \\
\hline Radial expansion coefficient & $\phi /{ }^{\circ} \mathrm{C}$ & -0.60 & -0.38 & -0.21 \\
\hline Axial expansion coefficient & $\phi /^{\circ} \mathrm{C}$ & -0.05 & -0.07 & -0.07 \\
\hline Fuel density coefficient & $\phi /{ }^{\circ} \mathrm{C}$ & -0.76 & -0.67 & \\
\hline Structural material density coefficient & $\phi /{ }^{\circ} \mathrm{C}$ & 0.03 & 0.06 & \\
\hline Sodium void worth & $\$$ & 1.10 & 4.93 & 7.29 \\
\hline Sodium density coefficient & $\phi /^{\circ} \mathrm{C}$ & 0.03 & 0.13 & 0.18 \\
\hline Doppler coefficient & $\phi /^{\circ} \mathrm{C}$ & -0.10 & -0.13 & -0.13 \\
\hline Sodium voided Doppler coefficient & $\phi /{ }^{\circ} \mathrm{C}$ & -0.07 & -0.09 & -0.09 \\
\hline
\end{tabular}

base case. As can be seen, the radial expansion yields a negative reactivity by increasing the leakage, in particular the axial leakage. The axial expansion enhances the radial leakage, so results in a negative reactivity. In this example, the height is the shorter dimension (more axial than radial leakage), and thus the radial expansion coefficient is more negative. It is also noted that the axial expansion increases the neutron absorption because of effective control rod insertion. The radial and axial expansion coefficients are respectively tied to the grid plate temperature and the fuel temperature, so they have different time constants. In TRU burner reactors, both the radial and axial expansion coefficients become more negative with decreasing TRU conversion ratio, since the reduced absorption in HM increases the leakage fraction.

The kinetics parameters and reactivity coefficients are compared in Table 13 between two burner reactors of different size [14, 15] and a large conventional breeder reactor [24]. The burners have a somewhat smaller delayed neutron fraction but larger prompt lifetime than the breeder. As the core size decreases, the radial expansion coefficient becomes more negative and the sodium density coefficient and void worth become smaller because of increasing leakage. The Doppler coefficient becomes more negative with increasing ${ }^{238} \mathrm{U}$ concentration. When the flowing sodium in the core is voided, the Doppler coefficient becomes less negative because of spectrum hardening.

\section{COMPUTATIONAL METHODS AND CODES}

As discussed in Section 2, fast rectors have distinct nuclear characteristics from thermal reactors, which make many of the assumptions employed in traditional LWR analysis methods not applicable. First of all, the scattering resonances of intermediate atomic mass nuclides, which result in the strongly jagged structure of fast reactor spectrum, and the lack of $1 / \mathrm{E}$ spectrum for the calculation of heavy isotope resonance absorption require very detailed modeling for slowing-down calculations. The hard neutron spectrum concentrated in the $\mathrm{keV}$ and $\mathrm{MeV}$ range makes it important to model anisotropic scattering, inelastic scattering, $(n, 2 n)$ reaction and unresolved resonance selfshielding. The long mean free path due to small absorption cross sections in fast region implies global coupling of the core and requires detailed whole-core depletion calculations. Therefore, a separate set of physics analysis tools has been developed with tailored assumptions for fast reactors. [25, 26] These fast reactor analysis methods and codes are reviewed in this section, focused on those used in the U.S.

\subsection{Cross Section Generation}

An initial step in the use of analytical models for reactor core calculations is the processing of evaluated nuclear data files for all pertinent nuclides into suitable forms for use in application codes. The NJOY code [27] is an internationally accepted code for processing nuclear data in the ENDF format into libraries for most application codes. It is noted that the ENDF format has become the standard for representing nuclear data worldwide, being utilized in the ENDF/B, JEF, and JENDL libraries. NJOY was developed at Los Alamos National Laboratory (LANL) and is periodically upgraded. Recently added features related to neutron data processing include capabilities for high-energy libraries, probability tables for unresolved 
range self-shielding treatment, and capabilities to handle the Reich-Moore limited resonance format.

Probability tables are used in continuous-energy Monte Carlo codes for handling the effects of self-shielding in the unresolved resonance energy range. [28] The effects of unresolved self- shielding are of importance in fastreactor core modeling. The current version of the NJOY code (NJOY2010) generates these tables using the PURR module. Reference 29 reports the effects of unresolved resonance self-shielding on 17 uranium and plutonium benchmarks [30, 31]. The self-shielding effects were investigated by MCNP [32] Monte Carlo calculations with and without unresolved resonance probability tables. It was reported that unresolved resonance self-shielding could produce substantial increase in reactivity for those benchmarks that have high fluxes within the unresolved resonance region; for example, the reactivity increase was $1.44 \%$ for ZEBRA-8H, $0.78 \%$ for ZEBRA-2, and $0.45 \%$ for ZPR-3/6F.

The generation of multigroup cross sections from evaluated nuclear data files remains one of the fundamental problems in reactor physics because of the need for accurate treatment of resonance effects. The methods used for cross-section processing must take into account both the resonance characteristics of intermediate nuclides and the self-shielding in fissile and fertile nuclides. The overlapping effect resulting from neighboring resonances either from the same nuclide or from different nuclides is another challenge in fast reactor analysis. The main approach used for fast reactor cross section generation in the 1970s was the Bondarenko self-shielding factor method. $[33,34]$ In this approach, a generalized cross section library is first prepared by calculating multigroup cross sections for a given material as a function of background cross section and temperature. Then, the cross sections for a particular composition at a given temperature are interpolated from the cross sections in the generalized library by calculating the background cross section for each material. Typical codes employing this approach are MINX [35], SPHINX [36] and NJOY [27]. An alternative approach was developed at Argonne National Laboratory (ANL) based on detailed spectrum calculations for individual compositions, and implemented in the ETOE2/MC ${ }^{2}-2 / \mathrm{SDX}$ code system. [37, 38] Compared to the self-shielding factor method, this approach is more rigorous in energy treatment. Recently, the self-shielding factor method has been improved to allow more detailed energy modeling by utilizing more energy groups. [39] Recent international improvements in this approach include the ECCO code [40], which has a multi-dimensional lattice analysis capability in conjunction with sub-group methods [41-43]. This spatial modeling capability explicitly treats the heterogeneity effect, and the sub-group method allows some re-capture of the resonance energy details.

In the ETOE-2/MC ${ }^{2}-2 / \mathrm{SDX}$ code system, the ETOE-2 code processes the ENDF/B data and prepares the $\mathrm{MC}^{2}-2$ libraries. These libraries include resolved resonance parameters, unresolved resonance parameters, ultra-finegroup (UFG) smooth cross sections, inelastic and $(\mathrm{n}, 2 \mathrm{n})$ scattering data, fission spectrum parameters, and elastic scattering distributions. The ETOE-2 code was recently updated to process the ENDF/B-VI format by implementing a scheme that converts the Reich-Moore parameters into multi-pole parameters such that they can be Doppler broadened. [44, 45]. The current UFG energy structure chosen to form the $\mathrm{MC}^{2}-2$ libraries for smooth tabulated non-resonant data is 2082 groups with constant lethargy from $14.19 \mathrm{MeV}$ to $0.4 \mathrm{eV}$, but the ETOE- 2 code allows any number of UFG lethargy intervals. Wide resonances are screened out and added to UFG smooth cross sections. The resonance data provided in the Reich-Moore formalism are converted into the multipole formalism [46] that preserves the general features required by the traditional resonance integral concept and the Doppler-broadening algorithm in the $\mathrm{MC}^{2}-2$ code without compromising rigor.

The $\mathrm{MC}^{2}-2$ code solves the slowing-down equation for specific compositions and temperatures with explicit representation of resonances. It solves the extended transport $\mathrm{P}_{1}$, extended transport $\mathrm{B}_{1}$, consistent $\mathrm{P}_{1}$, and consistent $B_{1}$ fundamental mode UFG equations and accommodates high-order anisotropic scattering representations. Resolved and unresolved resonances are treated explicitly by the generalized resonance integral formulation based on the narrow resonance (NR) approximation, including overlapping and Doppler broadening effects [47]. A fundamental mode homogeneous unit cell calculation is performed by solving the multigroup slowing-down equation above the resolved resonance energy and the continuous slowing-down equation below this range [48]. Equivalence theory is used to treat the heterogeneity effect, and isotropic approximation is used for fission, inelastic, and $(\mathrm{n}, 2 \mathrm{n})$ sources. An alternative hyperfine group (HFG) integral transport calculation option (RABANL) is available to model the resolved resonances more accurately in the low-energy ranges where the narrow resonance approximation is not valid. Under this HFG method, every resolved resonance is represented by multiple points, which allows the neutron spectrum within a HFG to be approximated as a constant. RABANL performs a homogeneous or heterogeneous (pin or slab) unit cell calculation over the resonance region using the isotropic source approximation.

The SDX code performs heterogeneous unit cell calculations in conjunction with $\mathrm{MC}^{2}-2$. Heterogeneous resonance cross sections are computed in an intermediate group level of $\sim 230$ groups for selected isotopes in the specified plate or pin types using equivalence theory or the rigorous RABANL heterogeneous treatment. These resonance cross sections are combined with the intermediategroup library data constructed from $\mathrm{MC}^{2}-2 \mathrm{UFG}$ calculations, and then an infinite slab or cylinder integral transport calculation is performed in the intermediate group level for 
the unit cell. The integral transport calculation is based on a modified version of the CALHET code [49] that applies the collision probability methods developed for RABANL. Spatial self-shielding factors and cell-averaged group cross sections are calculated.

Broad group cross sections for whole-core calculations can be obtained directly from the $\mathrm{MC}^{2}-2 / \mathrm{SDX}$ calculations. However, since few group cross sections are generally space-dependent, they are typically determined in multiple steps. In the first, composition and temperature dependent cross sections are generated in an intermediate ( 230) group structure from $\mathrm{MC}^{2}-2 / \mathrm{SDX}$ calculations. Using these intermediate group cross sections, two-dimensional whole-core transport calculations in RZ geometry are then performed using the TWODANT code [50]. Finally, using the resulting space dependent flux as weighting spectra, the intermediate group cross sections are collapsed into space-dependent broad group cross sections.

A new multigroup cross section generation code $\mathrm{MC}^{2}-3$ [51,52] has recently been developed at ANL by improving the resonance self-shielding and spectrum calculation methods of $\mathrm{MC}^{2}-2$ and integrating the onedimensional cell calculation capabilities of SDX. $\mathrm{MC}^{2}-3$ generates multigroup cross sections for every cell type by solving a homogeneous medium or a heterogeneous slab or cylindrical unit cell problem in UFG ( 2000) or HFG $(\sim 400,000)$ level. The resulting multigroup cross sections are written in the ISOTXS format for a user-specified group structure. Optionally, using the UFG cell cross sections, it can solve a two-dimensional whole-core problem in UFG level and generate region-dependent broad-group cross sections. Fig. 11 illustrates the overall computational flow of $\mathrm{MC}^{2}-3$. The calculation starts with preparing pointwise isotopic cross sections by reconstructing the Doppler broadened cross sections at specified isotopic temperatures in the resolved resonance range. The pointwise cross sections are directly used in the HFG calculation whereas for the UFG calculation, self-shielded cross sections are prepared by numerical integration of the pointwise cross sections based upon the narrow resonance approximation. For both the HFG and UFG calculations, unresolved resonances are self-shielded using the analytic resonance integral method. The code solves the consistent $\mathrm{P}_{1}$ multigroup transport equation for each cell problem to determine the fundamental mode spectrum in HFG or UFG level. The ultrafine group calculation can also be performed for two-dimensional whole-core problems to generate region-dependent broad-group cross sections.

\subsection{Whole-Core Calculation Tools}

The whole-core analysis capabilities are not specific to design systems, and can be used for a wide spectrum of systems. There are a number of well-established deterministic tools for diffusion and transport calculations. Most of the current whole-core diffusion theory codes are based on the advanced nodal methods that were developed mainly in early 1980 s to replace the expensive pin-by-pin finite difference method. These nodal codes include DIF3D-Nodal [53], PARCS [54], and SIMULATE-4 [55]. Using the homogenized assembly parameters obtained from assembly lattice calculations, they solve the fewgroup diffusion equation for three-dimensional Cartesian and/or hexagonal geometries. Among these codes, DIF3DNodal was specifically designed for fast reactor problems along with its companion kinetics code DIF3D-K [56],

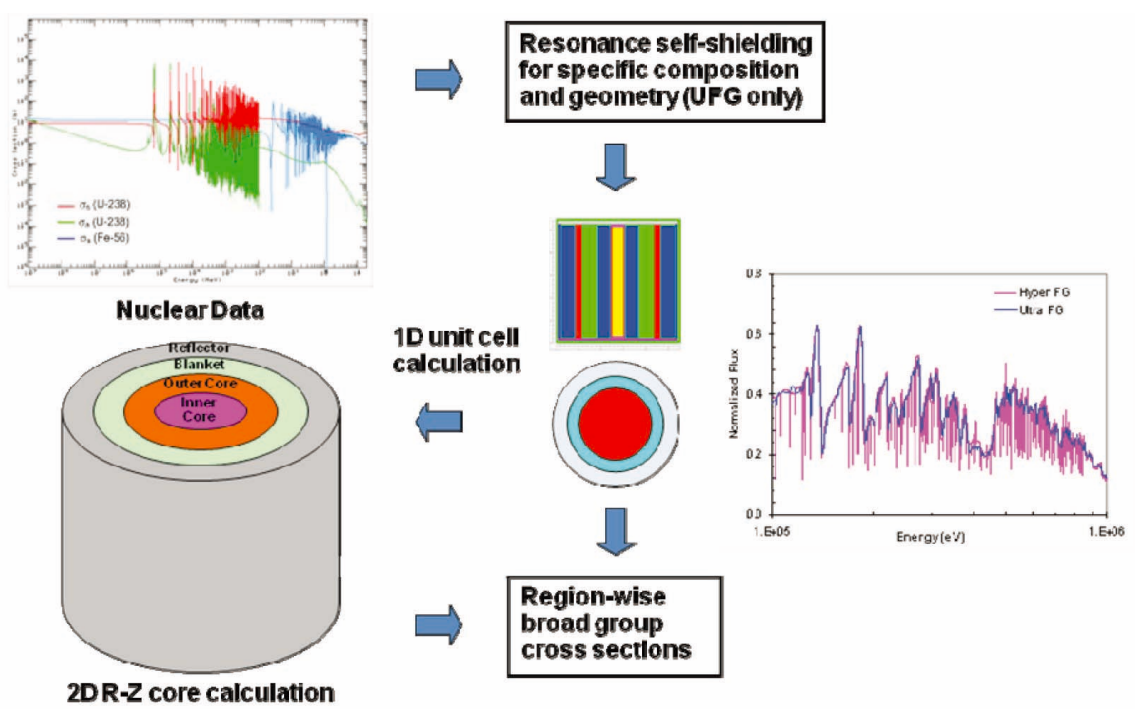

Fig. 11. Overall Computational Flow of $\mathrm{MC}^{2}-3$ 
which solves the time-dependent multigroup diffusion equations in two- and three-dimensional hexagonal and Cartesian geometries. DIF3D-K has been coupled to the SASSYS/SAS4A fast reactor safety and accident analysis code system [57].

Among dozens of different nodal methods, those based on the transverse integration procedure are most widely used in production analysis. In these methods, the transverse leakages are typically approximated with quadratic polynomials, and the resulting set of one-dimensional equations is generally solved with the nodal expansion method or the analytic nodal methods. However, the final algebraic equations are formulated in various forms and solved with different solution and acceleration schemes including Krylov subspace, domain decomposition, coarsemesh rebalancing, and non-linear iterative methods. These advanced nodal methods usually employ discontinuity factors to reduce assembly homogenization errors. Pin powers are recovered by imbedded local calculations or by superposition of nodal and lattice powers. Various three-dimensional, spatial kinetics capabilities were also developed based on the advanced nodal methods, and coupled with system thermal-hydraulics codes. These high fidelity kinetics methods are important for core transients involving significant variations of the flux shape.

Whole-core transport theory capabilities have been developed in both the first- and second-order formulations of the transport equation. The production codes based on the first-order formulation include ATTILA [58], PARTISN [59], THREEDANT [60], and Denovo [61]. These codes solve the multigroup transport equation on two- and threedimensional orthogonal or unstructured meshes. All of these codes use the discrete ordinates approximation for treating the angular variation of particle distribution. Various spatial discretization schemes are employed including the diamond and weighted diamond difference, linear and exponential discontinuous, discontinuous finite element, nodal, and characteristic methods. The source iteration approach is used to solve the discretized equations with various acceleration schemes such as the diffusion synthesis acceleration, coarse mesh rebalancing, partial current rebalancing, and multi-grid methods. The timedependent transport equation can also be solved using the PARTISN code, where the Crank-Nicholson method is used for time differencing.

The VARIANT code [62] is a typical production code based on the second-order formulation. It solves multigroup transport problems in two- and three-dimensional Cartesian and hexagonal geometries. It is based upon a variational nodal method that guarantees nodal balance and permits refinement using hierarchical complete polynomial trial functions in space and spherical harmonics or simplified spherical harmonics in angle. Flux and source expansions of up to sixth order and partial current expansions up to second order are allowed. Angular and scattering expansions of up to $\mathrm{P}_{5}$ are allowed. The even angular parity flux equations are solved within the nodes, and the continuity between nodes is provided by even- and odd-parity flux moments. The final algebraic equations are cast into a response matrix form and solved with red-black partial current iterations. A spatial kinetics code named VARIANT-K [63] was developed in connection with VARIANT to solve the time-dependent neutron transport equation, and coupled to the SASSYS/SAS4A code system.

As part of U.S. DOE's NEAMS program, a highfidelity deterministic neutron transport code UNIC is being developed. [51,64] The application scope targeted for UNIC ranges from the homogenized assembly approach prevalent in current reactor analysis methodologies to explicit geometry, time-dependent transport calculations that are directly coupled to thermal-hydraulics and structural mechanics calculations in reactor accident simulations. Three transport equation solvers have been developed based upon the unstructured finite-element mesh representation: PN2ND, SN2ND, and MOCFE. PN2ND and SN2ND solve the second-order even-parity transport equation with spherical harmonics and discrete ordinates angular approximations, respectively. MOCFE [65] is a method of characteristics solver for the first-order transport equation, of which targeted application is for explicit geometry, fine-group problems. The nodal transport code VARIANT is also being rebuilt in UNIC as NODAL which is focused on solving modern assembly homogenized problems.

Combined tests of $\mathrm{MC}^{2}-3$ and UNIC were performed against the criticality and reaction rate measurements in Loadings 104, 106, 120 and 132 of the ZPR-6 Assembly 7 High ${ }^{240} \mathrm{Pu}$ Core. [66] The radial traverses of enriched uranium (EU) fission, depleted uranium (DU) capture and fission, and ${ }^{239} \mathrm{Pu}$ fission reaction rates were measured using 69 activation foils. $\mathrm{BeO}$ was placed in the drawers adjacent to the central sodium channel in Loading 106 and to the central mockup control rod in Loading 132, in order to determine whether addition of such a $\mathrm{BeO}$ ring would enhance control rod worth. [67, 68] Table 14 compares

Table 14. Multiplication Factors of ZPR6/7 Loadings 104, 106, 120 , and 132

\begin{tabular}{c|r|r|r|r}
\hline Loading & \multicolumn{1}{c|}{104} & \multicolumn{1}{c|}{106} & 120 & \multicolumn{1}{c|}{132} \\
\hline MC $^{2}$-3/UNIC & 1.00147 & 1.00134 & 1.00127 & 1.00016 \\
\hline $\begin{array}{c}\text { MCNP5 } \\
\text { (as-built model) }\end{array}$ & 1.00016 & 1.00049 & 0.99967 & 1.00040 \\
\cline { 2 - 5 } & \pm 0.00007 & \pm 0.00007 & \pm 0.00007 & \pm 0.00007 \\
\hline \multirow{2}{*}{ Measurement } & 1.00072 & 1.00091 & 1.00099 & 1.00040 \\
\cline { 2 - 5 } & \pm 0.00002 & \pm 0.00003 & \pm 0.00003 & \pm 0.00002 \\
\hline
\end{tabular}

* Measurement uncertainty only, excluding composition and geometry uncertainties 


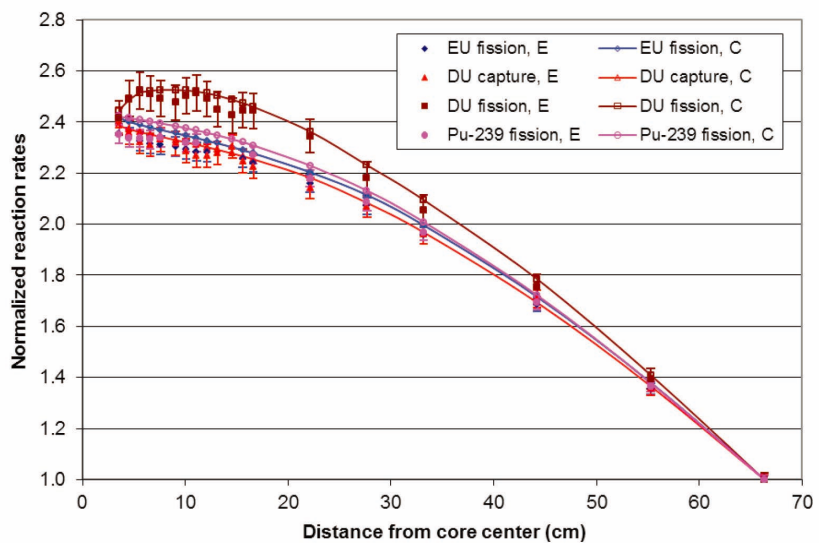

Fig. 12. Radial Distributions of Reaction Rates for Loading 104 of ZPR-6/7

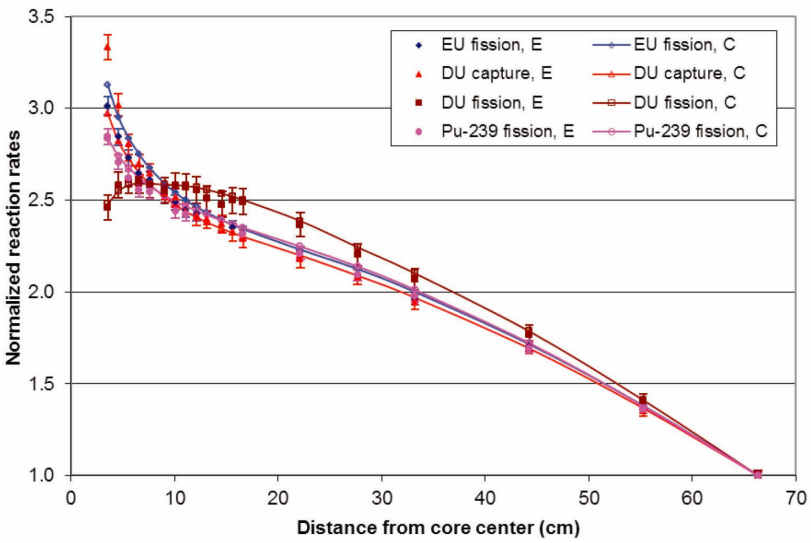

Fig. 13. Radial Distributions of Reaction Rates for Loading 106 of ZPR-6/7 the calculated UNIC eigenvalue solutions for Loadings 104, 106, 120, and 132 with MCNP5 [69] results and the experimentally measured values. For the UNIC calculations, 70-group drawer-averaged cross sections were generated using the 1-D transport capability of $\mathrm{MC}^{2}-3$ based on the ENDF/B-VII.0 data. The MCNP5 results were obtained with as-built models, where individual plate, drawer, matrix tube, etc. were modeled explicitly. The results indicated that $\mathrm{MC}^{2}-3 / \mathrm{UNIC}$ performed very well on the range of fast reactor problems. For all the four core loadings analyzed, the core reactivity was predicted within $1-\sigma$ (standard deviation) of the estimated experimental uncertainty $(\sim 80$ $\mathrm{pcm}$ ) including the geometry and composition uncertainties. This result is comparable to the accuracy of MCNP5 Monte Carlo solutions. As shown in Fig. 12 for Loading 104, the calculated reaction rate distributions in Loadings 104 and 120 of conventional fast reactor compositions agreed well with the foil activation measurements within $1-$ to $2-\sigma$ of the measurement uncertainties. However, for the Loadings 106 and 132 containing $\mathrm{BeO}$ plates, more than 3- $\sigma$ deviations were observed in the depleted uranium capture reaction rates near the $\mathrm{BeO}$ plates as shown in Fig. 13 for Loading 106. This indicates that two- or three-dimensional modeling capabilities need to be added to $\mathrm{MC}^{2}-3$.

Monte Carlo codes can be used for lattice and wholecore calculations. Such codes include KENO [70], MCNP5 [69], and VIM [71]. Additionally, for analyzing acceleratordriven systems, a Monte Carlo code MCNPX [72] has been developed by combining the high-energy physics code LAHET [73] and the Monte Carlo code MCNP. These codes allow accurate representation of nuclear data details and treatment of heterogeneity effects and complex geometries. They are however not routinely used at the current time for design calculations because of computational requirement.

\subsection{Depletion and Fuel Cycle Analysis Codes}

For LWR analyses, the depletion calculation is generally incorporated with the lattice calculation. Depletion calculations are performed in the assembly calculations using lattice codes, and homogenized assembly cross sections are generated as a function of burnup as well as the other state variables. Whole-core nodal calculations are then performed by determining the individual assembly cross sections by interpolating these homogenized cross sections for the corresponding burnup states.

For fast-reactor fuel cycle calculations, depletion calculation is performed in conjunction with the whole-core calculation. The REBUS-3 code [74] at ANL is a classic three-dimensional fuel cycle analysis code. REBUS-3 models nuclide transmutations on a three-dimensional, region-dependent basis by making use of DIF3D [75], DIF3D-Nodal [53], VARIANT [62], or TWODANT [50] as a flux calculation module. (In a version of REBUS-3 named REBUS-PC, the Monte Carlo code MCNP can also be invoked for flux calculation.) Two basic types of problems are solved: an equilibrium cycle problem to determine the equilibrium condition of a reactor operating under a fixed fuel management scheme and a nonequilibrium cycle problem to determine the explicit cycleby-cycle condition of a reactor under a specified periodic or non-periodic fuel management scheme. REBUS-3 provides considerable flexibility for specifying operational constraints and fuel management strategies for both incore and out-of-core portions of the fuel cycle. Search options for fresh fuel enrichment, control poison density, or reactor burn cycle time are available, allowing the user to achieve a specified multiplication factor or discharge burnup without time consuming (trial and error) repetitions of the analysis. These analysis capabilities for critical reactors can also be applied to subcritical acceleratordriven systems. [76] In this case, the spallation neutron 
sources are specified by the user as an external fixed source distribution. [77]

REBUS-3 has been validated using EBR-II, FFTF, and other fast reactor data. As an example of the accuracy of the overall computational schemes, Table 15 shows the calculation-to-experiment $(\mathrm{C} / \mathrm{E})$ comparisons for the fuel pin burnups of an Integral Fast Reactor (IFR) [78] test assembly irradiated in EBR-II. Fuel pin burnups were computed at several different axial positions using the DIF3D-Nodal flux solution option and the RCT code [79] for reconstruction of pin power and burnup characteristics. The calculated values were compared with the experimental results, which were derived from the measured amounts of fission products ${ }^{139} \mathrm{La}$ and ${ }^{148} \mathrm{Nd}$. In this table, the axial positions are specified as a fraction of the original fuel pin length $\left(L / L_{0}\right)$. All calculated values agreed with the measured values to within combined experimental uncertainties $(\sim 6 \%)$. These results represent aggregate tests of nuclear data, cross section generation, core representation, full-core diffusion/depletion method, and reconstruction scheme.

Isotopic point depletion tools like ORIGEN [80] and CINDER [81] are typically used for analyzing the detailed radioactivity properties of depleted fuel. However, they have recently been coupled to Monte Carlo tools for depletion calculations. Deficiencies in these capabilities are typically related to the nuclear data used in them. The ORIGEN-S code [82] is the current version of the ORIGEN code. Recent updates of cross sections, decay libraries, and neutron/gamma source data are contained in the code. The ORIGEN code and associated nuclear data libraries have been extensively validated against experimental data that include spent nuclear fuel isotopic assay data for actinides and fission products, radiation source spectra, and decay heat measurements. [83]

Table 15. C/E Comparisons for Burnup of an IFR Test Assembly in EBR-II

\begin{tabular}{c|c|c|c|c}
\hline Fuel Pin & $\mathrm{L}_{\mathrm{L}}$ & $\mathrm{C} / \mathrm{E}_{\mathrm{La}}$ & $\mathrm{C} / \mathrm{E}_{\mathrm{Nd}}$ & $\mathrm{C} / \mathrm{E}_{\mathrm{avg}}$ \\
\hline \multirow{3}{*}{$\begin{array}{c}\text { No.31 (T167) } \\
\text { (U-19Pu-10Zr) }\end{array}$} & 0.08 & 1.063 & 1.028 & 1.045 \\
\cline { 2 - 5 } & 0.57 & 1.057 & 1.054 & 1.055 \\
\cline { 2 - 5 } & 0.94 & 1.019 & 0.978 & 0.998 \\
\hline \multirow{2}{*}{$\begin{array}{c}\text { N. 40 (T13) } \\
\text { (U-8Pu-10Zr) }\end{array}$} & 0.12 & 1.054 & 1.030 & 1.042 \\
\cline { 2 - 5 } & 0.57 & 1.069 & 1.046 & 1.057 \\
\hline \multirow{3}{*}{$\begin{array}{c}\text { No. 13 (T119) } \\
(\mathrm{U}-10 Z r)\end{array}$} & 0.45 & 1.038 & 1.025 & 1.032 \\
\cline { 2 - 5 } & 0.92 & 1.010 & 1.001 & 1.006 \\
\hline
\end{tabular}

There has recently been more reliance on Monte Carlo tools for depletion calculations. The method is particularly useful for analysis of specified designs but not sufficiently efficient for use in parametric and trade studies required for developing an optimized design. Coupled Monte Carlo and depletion code systems such as MOCUP [84], MONTEBURNS [85], and MCODE [86] have been developed for the analysis of advanced systems. These code systems provide linkage capabilities that couple the MNCP Monte Carlo code with the ORIGEN2 depletion code. The Monte Carlo technique is attractive because of the ability to represent accurately nuclear data details and to treat heterogeneity effects and complex geometries. Propagation of the Monte Carlo statistical uncertainty during depletion calculations has not been addressed in these tools and future work to quantify (and hopefully control) this problem is required. Without this, results from such methods would be questioned due to un-quantified uncertainty.

\subsection{Perturbation Theory and Uncertainty Analysis Codes}

As mentioned in Section 2.5, the perturbation theory methods are usually used to compute kinetics parameters and reactivity coefficient distributions. The reactivity change (i.e., change in the eigenvalue of the neutron transport equation) due to some perturbations introduced in the system can be expressed by a conventional perturbation formula that involves the neutron and adjoint flux distributions along with the system perturbation. [20] The first-order perturbation theory formula is obtained using the flux and the adjoint flux for the unperturbed reference configuration. The exact perturbation theory formula is obtained if the solution to the perturbed configuration is used for either the flux or the adjoint flux. The perturbation theory formula readily provides the contribution of a local perturbation to the reactivity change, and the reactivity coefficient distribution corresponding to a perturbed input parameter is easily obtained.

When the response parameter is extended to other than the eigenvalue of the neutron transport equation (e.g., reaction rate ratios), the corresponding perturbation theory is called the generalized perturbation theory (GPT). [87] A class of GPT to describe the time-dependent behavior of the coupled neutron/nuclide field in the reactor is called the depletion perturbation theory (DPT). [88] The generalized perturbation theory methods are used to calculate the sensitivity coefficients of a response parameter with respect to input parameters (e.g., isotopic cross sections). The cross section sensitivity coefficients are used to estimate the uncertainty of response parameter due to uncertain cross sections or to reduce the response parameter uncertainty by the use of integral experiment data. [89]

VARI3D [90] is a generalized perturbation theory code that allows calculation of the effects on reactivity and 
reaction rate ratios of alterations in microscopic cross sections and/or material number densities. VARI3D is most frequently used to compute the reactivity coefficient distributions and kinetics parameters employed in reactor dynamics and safety analyses. The relevant neutron and adjoint flux distributions required to compute these quantities are provided by DIF3D. DPT [91,92] is a depletion perturbation theory code based upon the non-equilibrium and equilibrium fuel cycle analysis methodologies of REBUS-3. It calculates the sensitivity coefficients of a given response functional with respect to cross sections and initial nuclide densities. The adjoint nuclide density equations are solved using the iteration methods similar to those used for solving the nuclide density equations, and the generalized adjoint flux equations are solved using DIF3D. DPT currently generates sensitivity coefficients for five responses: the beginning and the end of cycle keffective, the burnup reactivity swing, the power fraction in any core region, and the end of cycle mass of any isotope in any core region.

GMADJ [93] is a code that computes the uncertainties of integral parameters by propagating nuclear data uncertainties by the use of the sensitivity coefficients from VARI3D and DPT calculations and evaluated nuclear data covariance. It provides a formal procedure based on the Bayesian statistics to quantify the uncertainties associated with predicted reactor performance parameters with full applications of integral experimental values. The GMADJ code and ANL integral experiment database proved very useful in the past for reducing integral parameter uncertainties and providing best predictions of integral parameters for proposed designs. [94]

Table 16 shows the relative uncertainties of the main integral parameters of a series of fast systems: ABR metal and oxide fuel cores, a SFR with low TRU conversion ratio, the sodium-cooled European Fast Reactor (EFR), a GFR, a LFR, and an accelerator-driven minor actinide burner (ADMAB). [95] The uncertainties were estimated using the AFCI-1.2 cross section covariance data [96]. The estimated multiplication factor uncertainties were significantly larger than the targeted prediction accuracy for Generation-IV systems [97]; it is above $1 \%$ for all systems considered and for SFR and ADMAB, it is above $2 \%$ because of the high content of minor actinides. The large uncertainty in the burnup reactivity swing of GFR is due to the large sensitivity coefficients of actinide cross sections, which are the combined results of large inventories of actinide isotopes, relatively large fraction of neutron spectrum above $\sim 1 \mathrm{MeV}$, and positive reactivity swing. These results indicate that the present uncertainties on the nuclear data should be significantly reduced in order to meet the targeted prediction accuracies for advanced systems. Combined use of scientifically derived covariance data and integral experiments in statistical evaluation of uncertainties is an efficient way to reduce the uncertainties of reactor performance predictions due to nuclear data uncertainties.
Table 16. Relative Uncertainties (\%) of Integral Parameters Estimated with AFCl-1.2 Cross Section Covariance Data

\begin{tabular}{|c|c|c|}
\hline System & Integral Parameter & $\sigma(\%)$ \\
\hline \multirow{2}{*}{$\begin{array}{l}\text { ABR } \\
\text { metal }\end{array}$} & BOC $k_{\text {eff }}$ & 1.54 \\
\hline & Coolant void worth & 10.32 \\
\hline \multirow{2}{*}{$\begin{array}{l}\text { ABR } \\
\text { oxide }\end{array}$} & BOC $\mathrm{k}_{\mathrm{eff}}$ & 1.49 \\
\hline & Coolant void worth & 5.60 \\
\hline \multirow{4}{*}{ SFR } & BOC $k_{\text {eff }}$ & 2.16 \\
\hline & Burnup reactivity swing & 5.10 \\
\hline & Doppler coefficient & 6.88 \\
\hline & Coolant void worth & 14.02 \\
\hline \multirow{4}{*}{ EFR } & BOC $k_{\text {eff }}$ & 1.29 \\
\hline & Burnup reactivity swing & 6.36 \\
\hline & Doppler coefficient & 4.03 \\
\hline & Coolant void worth & 5.40 \\
\hline \multirow{4}{*}{ GFR } & BOC $\mathrm{k}_{\mathrm{eff}}$ & 1.95 \\
\hline & Burnup reactivity swing & 35.33 \\
\hline & Doppler coefficient & 5.44 \\
\hline & Coolant void worth & 6.75 \\
\hline \multirow{4}{*}{ GFR } & BOC $k_{\text {eff }}$ & 1.67 \\
\hline & Burnup reactivity swing & 9.52 \\
\hline & Doppler coefficient & 6.2 \\
\hline & Coolant void worth & 9.81 \\
\hline \multirow{2}{*}{ ADMAB } & BOC $k_{\text {eff }}$ & 2.46 \\
\hline & Coolant void worth & 13.89 \\
\hline
\end{tabular}

\section{CONCLUSIONS}

The basic reactor physics specific to fast spectrum reactors have been reviewed briefly, focused on fissile material breeding and actinide burning. Design implications and reactivity feedback characteristics have also been compared between breeder and burner reactors. For all the fissionable nuclides, the fission-to-absorption ratio and the average number of neutrons released per fission increase with increasing incident neutron energy. Combination of increased fission-to-absorption ratio and increased number of neutrons per fission yields more excess neutrons in fast spectrum. The more excess neutrons enable breeding fissile material, and the breeding capability increases with increasingly harder neutron spectrum. 
Spectrum hardening is controlled by the heavy atom density relative to coolant and structure atom densities, which is in turn achieved by a high density fuel and a high fuel volume fraction.

The high fission-to-absorption ratios of TRU isotopes in fast spectrum also enable burning TRU elements effectively with less generation of higher actinides. Theoretically the TRU conversion ratio can be reduced to zero by removing all fertile blankets and utilizing uraniumfree fuel, but the neutronics properties of uranium-free fuel make it very difficult. In particular, the Doppler feedback coefficient of uranium-free fuel is almost zero or becomes slightly positive, depending on fuel compositions, and the delayed neutron fraction is reduced significantly. Recent studies on advanced burner reactors showed that TRU burners of conversion ratio in the range of 0.25-0.35 are feasible with favorable passive safety features and the TRU consumption rate reaches $\sim 80 \%$ of the maximum theoretical value. To reduce the TRU conversion ratio, it is necessary to increase the TRU faction in HM, which in turn requires reducing the fuel volume fraction. The increasing burnup reactivity loss with decreasing TRU conversion ratio should also be compensated for either by increasing the number of control assemblies or by reducing the cycle length.

The long mean free path in fast spectrum makes the core globally coupled so that local reactivity effects may impact the entire core. The long mean free path and the forward peaked scattering at high energies enhance the neutron leakage from the core and introduce relatively high flux gradient at the core and reflector interface, which makes the reactivity effect sensitive to minor geometric changes. As the TRU conversion ratio decreases, the effective delayed neutron fraction decreases due to reduced ${ }^{238} \mathrm{U}$ fission, but the prompt neutron lifetime increases due to reduced absorption in HM. The reduced ${ }^{238} \mathrm{U}$ fraction also makes the Doppler constant less negative. With decreasing TRU conversion ratio, the sodium density coefficient generally becomes more positive, but both the radial and axial expansion coefficients become more negative.

The distinct nuclear characteristics of fast reactors make many of the assumptions employed in traditional LWR methods not applicable. The strongly jagged structure of fast reactor spectrum due to the scattering resonances of intermediate atomic mass nuclides and the lack of 1/E spectrum for heavy isotope resonance absorption calculation require very detailed modeling for slowingdown calculations. The hard neutron spectrum makes it important to model anisotropic scattering, inelastic scattering, $(\mathrm{n}, 2 \mathrm{n})$ reaction and unresolved resonance selfshielding. The global coupling of the core due to long mean free path also requires detailed whole-core depletion calculations. Therefore, a separate set of physics analysis tools has been developed with tailored assumptions for fast reactors.
Neutronics tools used for the modeling of fast reactor designs in the U.S. have been reviewed. This review covers cross-section generation capabilities, whole-core deterministic (diffusion and transport) and Monte Carlo calculation tools, and fuel cycle analysis codes. The review indicates that the existing analysis tools are sufficiently accurate for early pre-conceptual design development and viability phase evaluations of advanced reactor designs that would include specific new design features. For refined analyses of the advanced systems, however, they require additional verification and validation tests. Additional improvements and capabilities might be needed in order to enhance the solution accuracy and efficiency by taking into account geometric complexity and complicated energy dependence of nuclear data.

Nuclear data are for the most part relatively well known for the most commonly used nuclides, but still improved data are required to reduce design uncertainties. In order to reduce the uncertainties of reactor performance predictions due to nuclear data uncertainties, it would be necessary to evaluate the uncertainties statistically by the use of integral experiments and scientifically derived covariance data.

\section{REFERENCES}

[1] J. Bouchard and R. Bennett, "A New Generation of Nuclear to Lead the Way," Energy Focus, Spring 2009 Edition, 85 (2009).

[2] J. Bouchard and R. Bennett, "Generation IV Advanced Nuclear Energy Systems," Nuclear Plant Journal, 26, 2 (2008).

[3 ] Leonard J. Koch, EBR-II Experimental Breeder Reactor II, Argonne National Laboratory (2004).

[4] M. E. Bunker, "Early Reactors from Fermi's Water Boiler to Novel Power Prototype," Los Alamos Science, Winter/ Spring 1983 Edition, 124 (1983).

[ 5 ] J. H. Kittel et al., "History of Fast Reactor Fuel Development," J. Nuclear Materials, 204, 1 (1993).

[6] C. E. Stevenson, The EBR-II Fuel Cycle Story, American Nuclear Society (1987).

[ 7 ] J. F. Sauvage, Phénix 30 Years of History: The Heart of a Reactor, CEA, France (2004).

[8 ] S. H. Fistedis, ed., "The Experimental Breeder Reactor-II Inherent Safety Demonstration," Nucl. Eng. Des. (Special issue), 101 (1987).

[9] "Fast Neutron Reactors (updated August 2011)," World Nuclear Association Website, http://www.world-nuclear/ org/info/inf98.html.

[10] M. B. Chadwick et al., "ENDF/B-VII.0: Next Generation Evaluated Nuclear Data Library for Nuclear Science and Technology," Nucl. Data Sheets, 107, 2931 (2006).

[11] C. E. Till, et al., "Fast Breeder Reactor Studies," ANL-8040, Argonne National Laboratory (1980).

[12] A. E. Waltar and A. E. Reynolds, Fast Breeder Reactors, Pergamon Press, New York, New York (1981).

[13] Fast Reactor Database, IAEA-TECDOC-866, International Atomic Energy Agency (1996).

[14] Y. I. Chang, et al., "Advanced Burner Test Reactor Preconceptual Design Report,” ANL-ABR-1 (ANL-AFCI- 
173), Argonne National Laboratory, 2006.

[15] W. S. Yang, T. K. Kim, and R. N. Hill, "Performance Characteristics of Metal and Oxide Fuel Cores for a 1000 MWt Advanced Burner Reactor," Proc. of Workshop on Advanced Reactors With Innovative Fuels ARWIF-2008, Fukui, Japan, February 20-22, 2008.

[16] W. S. Yang, "Trends in Transmutation Performance and Safety Parameters Versus Conversion Ratio of SodiumCooled Recycle Reactors," Proc. of $10^{\text {h }}$ Information Exchange Meeting on Actinide and Fission Product Partitioning and Transmutation, Mito, Japan, October 6-10, 2008.

[17] J. E. Cahalan, M. A. Smith, R. N. Hill, and F. E. Dunn, "Physics and Safety Studies of a Low Conversion Ratio Sodium Cooled Fast Reactor," Proc. of PHYSOR 2004: The Physics of Fuel Cycles and Advanced Nuclear Systems: Global Developments, Chicago, Illinois, April 25-29, 2004.

[18] M. J. Grimstone, J. D. Tullett, and G. Rimpault, "Accurate Treatments of Fast Reactor Fuel Assembly Heterogeneity in the ECCO Cell Code," Proc. Intl. Conference on the Physics of Reactors, Marseilles, France, April 23-27, 1990.

[19] W. S. Yang, T. K. Kim, S. J. Kim, and C. H. Lee, Personal Communication, Argonne National Laboratory (2007).

[20] K. O. Ott and R. J. Neuhold, Introductory Nuclear Reactor Dynamics, American Nuclear Society, La Grange Park, Illinois (1985).

[21] H. H. Hummel and D. Okrent, Reactivity Coefficients in Large Fast Reactors, American Nuclear Society, La Grange Park, Illinois (1970).

[22] J. Graham, Fast Reactor Safety, Academic Press, New York, New York (1971).

[23] H. S. Khalil and R. N. Hill, "Evaluation of Liquid-Metal Reactor Design Options for Reduction of Sodium Void Worth," Nucl. Sci. Eng., 109 (1995).

[24] D. C. Wade and E. K. Fujita, "Trends versus Reactor Size of Passive Reactivity Shutdown and Control Performance," Nucl. Sci. Eng., 103, 182 (1989).

[25] W. S. Yang and T. A. Taiwo, "Status of Reactor Analysis Methods and Codes in the U.S.A," Proc. of PHYSOR 2004: The Physics of Fuel Cycles and Advanced Nuclear Systems: Global Developments, Chicago, Illinois, April 25-29, 2004.

[26] T. Takeda, "Neutronics Codes Currently Used in Japan for Fast and Thermal Reactor Applications," Proc. of PHYSOR 2004: The Physics of Fuel Cycles and Advanced Nuclear Systems: Global Developments, Chicago, Illinois, April 25-29, 2004.

[27] R. E. MacFarlane and D. W. Muir, "The NJOY Nuclear Data Processing System Version 91," LA-12740-M, Los Alamos National Laboratory (1994).

[28] L. B. Levitt, "The Probability Table Method for Treating Unresolved Resonances in Monte Carlo Criticality Calculations," Trans. Am. Nucl. Soc. 14, 648 (1971).

[29] R. D. Mosteller and R. C. Little, "Impact of MCNP Unresolved Resonance Probability-Table Treatment on Uranium and Plutonium Benchmarks," LA-UR-98-2943, Los Alamos National Laboratory (1998).

[30] "Cross Section Evaluation Working Group Benchmark Specifications," BNL-19302 (ENDF-202), Brookhaven National Laboratory (1974).

[31] "International Handbook of Evaluated Criticality Safety Benchmark Experiments," NEA/NSC/DOC(95)03, OECD
Nuclear Energy Agency (1997)

[32] J. F. Briesmeister, ed., "MCNP - A General Monte Carlo N-Partile Transport Code, Version 4B," LA-12625-M, Los Alamos National Laboratory (1997).

[33] I. I. Bondarenko, et al, Group Constants for Nuclear Reactor Calculations, Consultants Bureau Enterprises, Inc., New York (1964).

[34] M. Segev, "A Theory of Resonance-Group Self-Shielding," Nucl. Sci. and Eng., 56, 72 (1975).

[35] C. R. Weisbin et al, "MINX: A Multigroup Interpretation of Nuclear X-Sections from ENDF/B," LA-6486-MS, Los Alamos Scientific Laboratory (1976).

[36] W. J. Davis, M. B. Yarbrough, and A. B. Bortz, "SPHINX, A One-Dimensional Diffusion and Transport Nuclear Cross Section Processing Code," WAPD-XS-3045-17, Westinghouse (1977).

[37] B. J. Toppel, H. Henryson II, and C. G. Stenberg, "ETOE2/MC ${ }^{2}-2 / S D X$ Multi-group Cross-Section Processing," Conf-780334-5, Proc. of RSIC Seminar-Workshop on Multi-group Cross Sections, Oak Ridge, TN, March 1978.

[38] H. Henryson II, B. J. Toppel, and C. G. Stenberg, "MC²-2: A Code to Calculate Fast Neutron Spectra and Multigroup Cross Sections," ANL-8144, Argonne National Laboratory (1976).

[39] S. M. Bowman, D. F. Hollenbach, M. D. DeHart, B. T. Rearden, I. C. Gauld, S. Goluoglu, "An Overview of What's New in SCALE 5," Trans. Am. Nucl. Soc., 87 (2002).

[40] G. Rimpault, "Algorithmic Features of the ECCO Cell Code for Treating Heterogeneous Fast Reactor Subassemblies," Intl. Conf. on Mathematics and Computations, Reactor Physics, and Environmental Analyses, Portland, Oregon, April 30-May 4, 1990.

[41] M. N. Nikolaev, et al., "Method of Subgroups for Accounting of Resonance Structure of Cross-sections in Neutron Calculations," Atomn. Energ. 29, 11 (1970).

[42] D. E. Cullen, "Application of the Probability Table Method to Multi-group Calculations of Neutron Transport," Nucl. Sci. Eng. 55, 387 (1974).

[43] P. Ribon and J. M. Maillard, "Les Tables De Probabilite Applications Au Traitement Des Sections Efficaces Pour La Neutronique," Report CEA-N, NEACRP-L-294 (1986).

[44] L. C. Leal and R. N. Hwang, "Computation of Multipole Parameters Using Preliminary ENDF/B-VI Data", Trans. Am. Nucl. Soc., 62, 573 (1990).

[45] R. N. Hwang, "Generalized Pole Representation Revisited", Trans. Am. Nucl. Soc., 88, 491, (2003).

[46] R. N. Hwang, "A Rigorous Pole Representation of Multilevel Cross Sections and Its Practical Applications," Nucl. Sci. Eng., 96, 192 (1987).

[47] R. N. Hwang, "Efficient Methods for the Treatment of Resonance Integrals," Nucl. Sci. Eng., 52, 157 (1973).

[48] W. M. Stacey Jr., "Continuous Slowing Down Theory Applied to Fast-Reactor Assemblies," Nucl. Sci. Eng., 41, 381 (1970).

[49] F. L. Fillmore, "The CALHET-2 Heterogeneous Perturbation Theory Code and Application to ZPR-3-48," AI-69-13 (1969).

[50] R. E. Alcouffe, F. W. Brinkley, D. R. Marr, and R. D. O'Dell, “User's Guide for TWODANT: A Code Package 
for Two-Dimensional, Diffusion-Accelerated, NeutralParticle Transport," LA-10049-M, Los Alamos National Laboratory (1990).

[51] W. S. Yang, M. A. Smith, C. H. Lee, A. Wollaber, D. Kaushik, and A. S. Mohamed, "Neutronics Modeling and Simulation of SHARP for Fast Reactor Analysis," Nuclear Engineering and Technology, 42, 520 (2010).

[52] C. H. Lee and W. S. Yang, "MC ${ }^{2}-3$ : Multigroup Cross Section Generation Code for Fast Reactor Analysis," ANL-NE-11-41, Argonne National Laboratory (2011).

[53] R. D. Lawrence, "The DIF3D Nodal Neutronics Option for Two- and Three-Dimensional Diffusion Theory Calculations in Hexagonal Geometry," ANL-83-1, Argonne National Laboratory (1983).

[54] T. J. Downar et al., "PARCS: Purdue Advanced Reactor Simulator," Proc. of PHYSOR 2002 ANS International Topical Meeting on the New Frontiers of Nuclear Technology, Seoul, Korea, October 7-10, 2002.

[55] T. Bahadir, S. Lindahl, and Palmtag, "SIMULATE-4 Multigroup Nodal Code with Microscopic Depletion Model," Mathematics and Computation, Supercomputing, Reactor Physics and Nuclear and Biological Applications, Avignon, France, September 12-15, 2005.

[56] T. A. Taiwo and H. S. Khalil, "DIF3D-K: A Nodal Kinetics Code for Solving the Time-Dependent Diffusion Equation," Proc. Int. Conf. Mathematics and Computations, Reactor Physics, and Environmental Analyses, Portland, Oregon, April 30-May 4, 1995.

[57] J. E. Cahalan, et al., "Advanced LMR Safety Analysis Capabilities in the SASSYS- 1 and SAS4A Computer Codes," Proc. of the International Topical Meeting on Advanced Reactors Safety, Pittsburgh, PA (1994).

[58] T. A. Wareing, J. M. McGhee, and J. E. Morel, “ATTILA: A Three-Dimensional, Unstructured Tetrahedral Mesh Discrete Ordinates Transport Code," Trans. Am. Nucl. Soc., 75, 146 (1996).

[59] R. E. Alcouffe, R. S. Baker, J. A. Dahl, and S. A. Turner, "PARTISN Abstract," PHYSOR 2000 ANS International Topical Meeting on Advances in Reactor Physics and Mathematics and Computation into the Next Millennium, Pittsburgh, Pennsylvania, May 7-11, 2000.

[60] R. E. Alcouffe, R. S. Baker, F. W. Brinkley, D. R. Marr, R. D. O'Dell, and W. F. Walters, "DANTSYS: A Diffusion Accelerated Neutral Particle Transport Code System," LA-12969-M (1995).

[61] T. M. Evans, A. S. Stafford, R. N. Slaybaugh, and K. T. Clarno, "Denovo: A New Three-Dimensional Parallel Discrete Ordinates Code in SCALE," Nuclear Technology, 171, 171 (2010)

[62] G. Palmiotti, E. E. Lewis, and C. B. Carrico, "VARIANT: VARIational Anisotropic Nodal Transport for Multidimensional Cartesian and Hexagonal Geometry Calculation," ANL-95/40, Argonne National Laboratory (1995).

[63] T. Taiwo, R. Ragland, G. Palmiotti, P. J. Finck, "Development of a Three-Dimensional Transport Kinetics Capability for LWR-MOX Analyses," Trans. Am. Nucl. Soc., 79, 298 (1999).

[64] M. Smith, D. Kaushik, A. Wollaber, W. S. Yang, and B. Smith, "New Neutronics Analysis Tool Development at Argonne National Laboratory," Proc. of International
Conference on Fast Reactors and Related Fuel Cycles (FR09), Kyoto, Japan, December 7-11, 2009.

[65] M. A. Smith, A. Marin-Lafleche, W. S. Yang, D. Kaushik, and A. Siegel, "Method of Characteristics Development Targeting the High Performance Blue Gene/P Computer at Argonne National Laboratory," Proc. of International Conference on Mathematics, Computational Methods \& Reactor Physics (M\&C 2011), Rio de Janeiro, Brazil, May 8-12, 2011.

[66] A. Mohamed, W. S. Yang, M. A. Smith and C. H. Lee, "Analysis of Reaction Rate Distribution Measurements in ZPR-6 Assembly 7 Cores with MC ${ }^{2}$-3/UNIC Code System," Proc. of International Conference on Mathematics, Computational Methods \& Reactor Physics (M\&C 2011), Rio de Janeiro, Brazil, May 8-12, 2011.

[67] R. M. Lell, J. A. Morman, R. W. Schaefer and R. D. McKnight, "ZPR-6 Assembly 7 High ${ }^{240} \mathrm{Pu}$ Core Experiments: A Fast Reactor Core with Mixed (Pu,U)-Oxide Fuel and a Central High ${ }^{240} \mathrm{Pu}$ Zone," International Handbook of Evaluated Reactor Physics Benchmark Experiments, NEA/NSC/DOC (2006)1, OECD-NEA (2009).

[68] R. M. Lell, “ZPR-6 Assembly 7 High ${ }^{240} \mathrm{Pu}$ Core: A Cylindrical Assembly with Mixed (Pu,U)-Oxide Fuel and a Central High ${ }^{240} \mathrm{Pu}$ Zone," International Handbook of Evaluated Criticality Safety Benchmark Experiments, NEA/NSC/DOC(95)03, OECD-NEA (2009).

[69] F. B. Brown, et al. "MCNP5-1.51 Release Notes," LAUR-09-00384, Los Alamos National Laboratory (2009).

[70] S. Goluoglu, L. M. Petrie, Jr., M. E. Dunn, D. F. Hollenbach, and B. T. Rearden, "Monte Carlo Criticality Methods and Analysis Capabilities in SCALE," Nucl. Technol., 174, 214 (2011).

[71] R. N. Blomquist, "VIM Continuous Energy Monte Carlo Transport Code," Proc. Intl. Conf. on Mathematics, Computations, Reactor Physics and Environmental Analysis, Portland, OR, April 30-May 4, 1995.

[72] L. S. Waters, ed., "MCNPX Users Manual (Version 2.1.5)," APT Program Report, Los Alamos National Laboratory (1999).

[73] R. E. Prael and H. Lichtenstein, "User Guide to LCS: The LAHET Code System," LA-UR-89-3014, Los Alamos National Laboratory (1989).

[74] B. J. Toppel, "A User's Guide to the REBUS-3 Fuel Cycle Analysis Capability," ANL-83-2, Argonne National Laboratory (1983).

[75] K. L. Derstine, "DIF3D: A Code to Solve One-, Two-, and Three-Dimensional Finite-Difference Diffusion Theory Problems," ANL-82-64, Argonne National Laboratory (1984).

[76] W. S. Yang and H. S. Khalil, "Analysis of the ATW Fuel Cycle Using the REBUS-3 Code System," Trans. Am. Nucl. Soc., 81, 277 (1999).

[77] W. S. Yang, J. C. Beitel, E. Hoffman, and J. A. Stillman, "Source Coupling Interface between MCNP-X and Deterministic Codes for ADS Analyses," Trans. Am. Nucl. Soc., 88, 592 (2003).

[78] W. H. Hannum, ed., "The Technology of the Integral Fast Reactor and its Associated Fuel Cycle," Prog. Nucl. Energy. (Special issue), 31 (1997).

[79] W. S. Yang, P. J. Finck, and H. Khalil, "Reconstruction of Pin Power and Burnup Characteristics from Nodal 
Calculations in Hexagonal Geometry," Nucl. Sci. Eng., 111, 21 (1992).

[80] "RSICC Computer Code Collection - ORIGEN 2.1, Isotope Generation and Depletion Code Matrix Exponential Method," CCC-371, Contributed by Oak Ridge National Laboratory (1999).

[81] W. B. Wilson et al., "Status of CINDER'90 Codes and Data," Proc. 4th Workshop on Simulating Accelerator Radiation Environments, Knoxville, Tennessee, September 13-16, 1998.

[82] I. C. Gauld, O. W. Hermann, and R. M. Westfall, "ORIGEN-S: SCALE System Module to Calculate Fuel Depletion, Actinide Transmutation, Fission Product Buildup and Decay, and Associated Radiation Source Terms," ORNL/NUREG/CSD-2/V2/R7, Oak Ridge National Laboratory (2002).

[83] I. C. Gauld, G. Radulescu, G. Ilas, B. D. Murphy, M. L. Williams, and D. Wiarda, "Isotopic Depletion and Decay Methods and Analysis Capabilities in SCALE," Nucl. Technol., 174, 169 (2011).

[84] R. L. Moore, B. G. Schnitzler, C. A. Wemple, R. S. Babcock, And D. E. Wessol, "MOCUP: MCNP-ORIGEN2 Coupled Utility Program," INEL-95/0523, Idaho National Engineering Laboratory (1995).

[85] D. I. Poston, H. R. Trellue, "User's Manual Version 2.0, for MONTEBURNS Version 1.0," LA-UR-99-4999, Los Alamos National Laboratory (1999).

[86] Z. Xu and P. Hejzlar, "MCODE, Version 2.2: An MCNPORIGEN Depletion Program," MIT-NFC-TR-104, Massachusetts Institute of Technology (2008).

[87] A. Gandini, "Generalized Perturbation Theory for Nonlinear Systems from the Importance Conservation Principle," Nucl. Sci. Eng, 77, 316 (1981).

[88] M. L. Williams, "Development of Depletion Perturbation
Theory for Coupled Neutron/Nuclide Fields," Nucl. Sci. Eng, 70, 20 (1979).

[89] G. Palmiotti, M. Salvatores, G. Aliberti, H. Hiruta, R. McKnight, P. Oblozinsky, W. S. Yang, "A Global Approach to the Physics Validation of Simulation Codes for Future Nuclear Systems," Ann. Nucl. Energy, 36, 355 (2009).

[90] C. H. Adams, Private Communication, Argonne National Laboratory (1975).

[91] W. S. Yang and T. J. Downar, "Generalized Perturbation Theory for Constant Power Core Depletion," Nucl. Sci. and Eng., 99, 353 (1988).

[92] W. S. Yang and T. J. Downar, "Depletion Perturbation Theory for the Constrained Equilibrium Cycle," Nucl. Sci. Eng., 102, 365-380 (1989).

[93] W. P. Poenitz and P. J. Collins, "Utilization of Experimental Integral Data for Adjustment and Uncertainty Evaluation of Reactor Design Quantities," NEACRP-L-307, Proc. NEACRP Specialists Meeting, Jackson Hole, WY (1988).

[94] P. J. Collins, S. E. Aumeier, and H. F. McFarlane, "Evaluation of Integral Measurements for the SP-100 Space Reactor," Proc. 1992 Topical Meeting on Advances in Reactor Physics, Charleston, SC (1992).

[95] W. S. Yang, G. Aliberti and R. D. McKnight, "Application of AFCI Covariance Data to Uncertainty Evaluation of Fast System Integral Parameters," J. Korean Physical Society, 59, 1288 (2011).

[96] P. Oblozinsky et al., "Progress on Nuclear Data Covariances: AFCI-1.2 Covariance Library," BNL-908972009, Brookhaven National Laboratory (2009).

[97] "Uncertainty and Target Accuracy Assessment for Innovative Systems Using Recent Covariance Data Evaluation," OECD/NEA Report No. 6410, OECD (2008). 